This is the authors accepted manuscript version of the article published as:

McDonald-Wharry, J., Manley-Harris, M. \& Pickering, K. (2013). Carbonisation of biomassderived chars and the thermal reduction of a graphene oxide sample studied using Raman spectroscopy. Carbon, 59, 383-405. DOI: 10.1016/j.carbon.2013.03.033

*Corresponding Author. Email address: jsm25@waikato.ac.nz (J. McDonald-Wharry) 


\title{
Carbonisation of biomass-derived chars and the thermal reduction of a graphene oxide sample studied using Raman spectroscopy
}

\author{
John McDonald-Wharry ${ }^{\mathrm{a} *}$, Merilyn Manley-Harris ${ }^{\mathrm{a}}$, Kim Pickering ${ }^{\mathrm{b}}$. \\ ${ }^{a}$ Chemistry Department, University of Waikato, Private Bag 3105, Hamilton, New Zealand \\ ${ }^{\mathrm{b}}$ School of Engineering, University of Waikato, Private Bag 3105, Hamilton, New Zealand
}

\begin{abstract}
Chars and carbonised chars were produced from three different oxygen-rich precursors (Pinus radiata wood, Phormium tenax leaf fibres, and sucrose crystals). These nongraphitisable carbons were analysed with Raman spectroscopy in order to study the nanostructural development which occurs with increasingly severe heat treatments up to approximately $1000{ }^{\circ} \mathrm{C}$. The thermal reduction of a graphene oxide sample was similarly studied, as this is considered to involve the development of nanometre-scale graphene-like domains within a different oxygen-rich precursor. Increasing the heat treatment temperatures used in the charring and carbonisation processes, led to significant changes in a number of parameters measured in the Raman spectra. Correlations based on these parameter changes could have future applications in evaluating various char samples and estimating the heat treatment temperatures employed during their manufacture. After production heat treatment temperatures exceeded $700{ }^{\circ} \mathrm{C}$, the Raman spectra of the carbonised chars appeared to be largely precursor independent. The spectra of these carbonised chars were similar to the spectra obtained from thermally-reduced graphene oxides, especially when compared to a wide range of other carbonaceous materials analysed using this particular methodology. Partial reduction of a graphene oxide sample due to reasonably mild laser exposures during Raman analysis was also observed.
\end{abstract}

*Corresponding Author. Email address: jsm25@waikato.ac.nz (J. McDonald-Wharry) 


\section{Introduction}

Chars and carbonised chars produced from lignocellulosic biomass (also called "biocarbons") are researched for a wide range of applications and potential applications, with activated carbons and metallurgical reductants being well established uses of these products $[1,2]$. The large surface areas and electrical conductivity of carbonised chars has led to their consideration as electrode materials for lithium-ion batteries [3], sodium-ion batteries [4], electrochemical capacitors [5], and solid carbon fuel cells [6]. Chars intended for agricultural and horticultural application (also called "biochars") have been investigated as soil conditioners/amendments $[1,7]$ and as a means of sequestering carbon in a long-lasting solid form [7]. Many of these applications are reliant on properties such as fixed carbon content, electrical conductivity, and surface area which develop during the carbonisation process and these properties are considered to be strongly influenced by the peak temperature or heat treatment temperature (HTT) used in the pyrolysis/carbonisation procedure $[1,8]$. Thus, there is a need to assess the extent of carbonisation in various char samples and estimate the "effective HTT" used in their production. The application of Raman spectroscopy to estimate HTT for quality control has previously been demonstrated in the case of Japanese cedar (Cryptomeria japonica) wood and bark chars by Yamauchi and Kurimoto [9]. Similar indepth Raman analysis of chars and carbonised chars produced at a range of HTTs has also been carried out by Zickler et. al. using European spruce wood (Picea abies) as a precursor [10]. 
It has long been recognised that when certain organic precursors (especially precursors rich in oxygen, such as carbohydrates) are pyrolysed and carbonised they form non-graphitising carbons which tend to be hard, porous, low density chars. These properties are in contrast to the softer, more compact, and graphitisable cokes that tend to be formed from carbonising other precursors such as hydrocarbons $[2,11,12]$. The importance of oxygen content in this process has more recently been clearly demonstrated by a study where a high pressure oxygen treatment at $200{ }^{\circ} \mathrm{C}$, was used to convert petroleum pitch from a precursor of graphitisable carbon to a precursor of non-graphitisable carbon [13]. Since the pioneering Xray diffraction investigation and structural model development of Franklin [11], simple carbohydrates such as sucrose have been used as standard precursors for the preparation of non-graphitising carbons in experiments that investigate how this material's fine structure and properties change as HTTs used in the production process are increased. Transmission electron microscopy, Raman spectroscopy and a wide variety of X-ray scattering/adsorption/diffraction techniques have been previously employed in these investigations [12, 14-17]. 
When lignocellulosic biomass and other carbohydrate-based or oxygen-rich precursors are carbonised, a number of drastic increases in material properties such as electrical conductivity, hardness, and elastic modulus typically occur between HTTs of $300{ }^{\circ} \mathrm{C}$ and $1000{ }^{\circ} \mathrm{C}[1,2,8,18]$. It has been repeatedly discussed that some kind of critical cross-linking and/or molecular arrangements occur during these "early" stages of the heat treatment (below $1000{ }^{\circ} \mathrm{C}$ ) which are significant enough to allow the resulting carbonised char structure to generally resist collapse into bulk crystalline graphite even when the carbonised char is subsequently heated to temperatures over $3000{ }^{\circ} \mathrm{C}[2,11,12,18]$. Recently, the difficulties and problems encountered during attempts to convert graphene oxide into large, flat, and pristine graphene sheets have led to many theoretical and experimental investigations [19, 20]. The study of these reduced graphene oxide problems, including the persistence of thermally stable carbonyl functional groups, the formation of non-hexagonal carbon ring structures (pentagons, heptagons, and octagons) within graphene-like sheets, and the somewhat permanent curvature/distortions/defects related to these structural features, may offer insights into the nanostructure of many non-graphitising carbons and the potential role of oxygen in their formation. 
Carbonisation is generally regarded as the process where carbon-rich solid residues form through the pyrolysis of organic materials. The extent of carbonisation is considered to be controlled by the final pyrolysis temperature applied [21]. However, more specific definitions of the carbonisation process and division of the process into stages can vary across the literature, due to differences in precursors, differences in which properties/features are of most interest, and which terminology is preferred by the various authors. For the purposes of this paper the carbonisation process of most interest is the one which tends to occur between HTTs of $\approx 400^{\circ} \mathrm{C}$ and $\approx 900^{\circ} \mathrm{C}$. The term carbonised char is used throughout this paper to refer to chars produced at higher HTTs (closer to $800^{\circ} \mathrm{C}$ ) where the nanostructural development associated with this carbonisation process is nearing some sort of completion. This completion generally corresponds to the end of stage 1 under Rouzaud and Oberlin's classifications [12], the middle of stage 3 under Jenkins and Kawamura's classifications [2], and stage 4 under the classifications detailed by Rhim et. al.[8]. Properties including hardness, elastic modulus, electrical conductivity, and specific surface area generally reach maximums and/or their previously rapid rates of increase slow greatly in the HTT range between $700-1000^{\circ} \mathrm{C}[1,2,8,18]$, which would indicate that in carbonised chars a nanostructural development process is reaching completion. Although both are carbonaceous solids rich in $\mathrm{sp}^{2}$ carbon structures, lower HTT chars are very different from higher HTT carbonised chars both in terms of properties and in the nanostructure which provides such properties. As Raman spectroscopy (using visible or infra-red excitation) is particularly sensitive to $\mathrm{sp}^{2}$ carbon structures (and their features measured on the scale of nanometres [22]), it provides an opportunity to study this nanostructural development, compare chars at various extents of this development with other carbonaceous nanostructures, and identify Raman parameters which could have future use as part of quality control in char manufacture. 
The aim of this study was to develop a routine Raman methodology (specifically using 785 $\mathrm{nm}$ excitation and analysis of larger areas using a laser spot approximately $200 \mu \mathrm{m}$ in diameter) for assessing the extent of nanostructural development (and/or degree of carbonisation) in chars produced from a diverse range of precursors and estimate the "effective HTTs" used in their production. An additional aim was to use Raman spectroscopy as part of testing a hypothesis that carbonised chars are chemically and nanostructurally more similar to thermally-reduced graphene oxides than to other proposed structural analogues such as graphites and fullerenes.

\section{Experimental}

\subsection{Materials and equipment}

Samples of synthetic graphite powder (BDH laboratory Supplies, UK), graphene oxide platelets (Graphene Laboratories, USA), $\mathrm{C}_{60}$ fullerenes (99.5\% purity, Sigma Aldrich), [5,6]$\mathrm{C}_{70}$ fullerenes (99\% purity, Sigma Aldrich), single walled carbon nanotubes (CarboLex APgrade, produced through an electric arc discharge method, Sigma Aldrich), and spherical glassy carbon powder (> 99\% purity on metal-free basis, Sigma Aldrich), were analysed as received. Colloidal graphite (Agar Scientific) was painted onto a metal disk and allowed to dry before analysis. Tenax HTA 5131 carbon fibres (Akzo Nobel) were analysed as an example of commercial PAN-derived carbon fibres and were acetone washed before analysis. 
Samples of radiata pine (Pinus radiata) softwood chars produced at a range of HTTs in a gasfired drum pyrolyser at Massey University (Palmerston North, New Zealand) were analysed as received. The radiata pine wood for this set of samples had been sawn (along the grain) into beams with a square cross-section $(13 \mathrm{~mm} \times 13 \mathrm{~mm})$ prior to heat treatment. Once converted into chars, these beams were broken, providing surfaces which were part of the beam's interior during pyrolysis/carbonisation, and these interior surfaces were analysed. Sucrose (99\% purity, Sigma Aldrich, USA), graphene oxide platelets (Graphene Laboratories, USA), and mechanically-stripped harakeke (Phormium tenax) leaf fibres (Foxton Flax Stripping Museum, NZ) were used as precursors to produce the thermally treated samples. The heat treatment of these samples was carried out using electrically heated tube and muffle furnaces.

Raman spectra were acquired with a Ramanstation 400R (PerkinElmer) spectrometer equipped with an air cooled CCD detector and data points were recorded at $1 \mathrm{~cm}^{-1}$ intervals. The excitation source was a $785 \mathrm{~nm}$ near infrared laser focused on surfaces of samples with a spot approximately $200 \mu \mathrm{m}$ in diameter. Calibration was validated against a polystyrene standard disk (PerkinElmer), and a spectrum from a pellet of high density polyethylene (HDPE, Sigma Aldrich) was acquired as the first sample on a daily basis and compared to previous HDPE spectra to confirm that the instrument was functioning correctly before carbonaceous samples were analysed. 


\subsection{Sample preparation}

Heating rates employed in the thermal treatments using electric furnaces (tube and muffle) were $\approx 30{ }^{\circ} \mathrm{C} / \mathrm{min}$ up to $500{ }^{\circ} \mathrm{C}, \approx 10{ }^{\circ} \mathrm{C} / \mathrm{min}$ up to $700{ }^{\circ} \mathrm{C}$, and $\approx 7{ }^{\circ} \mathrm{C} / \mathrm{min}$ up to $1000{ }^{\circ} \mathrm{C}$. After the thermocouple reading reached the designated HTT, the temperature was held for the hold/dwell time (typically $20 \mathrm{~min}$ ). After the hold/dwell time the furnace and samples were allowed to cool in place. The furnaces and vessels were not opened until the thermocouple readings were below $100{ }^{\circ} \mathrm{C}$ to minimise oxidative damage. Sample names which include a temperature in ${ }^{\circ} \mathrm{C}$ should be read as the temperature representing the HTT used to prepare the sample. These HTT values were calculated as the mean thermocouple reading over the 12 minutes where these readings were at their maximum (usually during the 20 minute dwell time).

Chars produced from harakeke leaf fibres and sucrose sugar at HTTs $<800{ }^{\circ} \mathrm{C}$ were produced inside quartz vessels within a furnace purged using a flow of $\mathrm{N}_{2}$ gas prior to heating. No $\mathrm{N}_{2}$ gas flow was applied while heat treating these samples. HTT $\approx 900{ }^{\circ} \mathrm{C}$ chars were produced in stainless steel vessels or ceramic crucibles capped under a flow of $\mathrm{N}_{2}$ gas. Small samples of the chars produced at HTTs of $\approx 700{ }^{\circ} \mathrm{C}$ from sucrose crystals, harakeke fibres, and radiata pine wood, were each sealed under vacuum in individual quartz tubes, before being heat treated together in the muffle furnace at a HTT of $\approx 1000{ }^{\circ} \mathrm{C}$. This approach of heat treating samples in sealed tubes is similar to one previously employed by Violette [1], and although quartz tubes and vacuum was employed in this current work, the tubes can still explode due to internal pressures (small precursor mass loading and pre-pyrolysing the chars was used to mitigate this risk). 
Thermally-reduced graphene oxides were prepared by heating samples of graphene oxide platelets sealed under vacuum inside quartz tubes. These thermally-reduced graphene oxide samples were prepared at a range of HTTs using the same electric furnace procedures as the chars.

Small samples of CarboLex single walled carbon nanotubes (SWCNTs) and the synthetic graphite were air oxidised by moving them into an open tube furnace, pre-heated to 550-600 ${ }^{\circ} \mathrm{C}$ and holding them in the furnace for 15 minutes before they were removed from the heated part of the furnace and allowed to cool. This method was adapted from a "flash oxidation" method developed by Osswald et. al. for the purification and functionalisation of multiwalled carbon nanotubes [23].

\subsection{Raman spectroscopy methodology}

Samples were analysed while placed on aluminium foil, glass microscope slides, inside $2 \mathrm{ml}$ glass vials, or inside the quartz tubes in which they were thermally treated. The Raman instrument was visually focused onto the surface of each location analysed on the carbonaceous samples. Laser power set to approximately $20 \mathrm{~mW}$ (20\% of maximum, estimated to be $\approx 6 \times 10^{5} \mathrm{~W} / \mathrm{m}^{2}$ on the $\approx 200 \mu \mathrm{m}$ diameter spot) was used to acquire spectra from all samples (after initial trials) for consistency across the range of materials analysed. Each spectrum was acquired as the sum of five repeats of 60 second exposures on the same location on the sample. The exceptions were fullerenes $\left(\mathrm{C}_{60}\right.$ and $\left.\mathrm{C}_{70}\right)$ samples which provided abundant signal after only 2 seconds exposure and low HTT chars with rising baselines where exposure times were reduced to 20 seconds. In both these cases, exceptions were used because 60 second exposures saturated the instrument's detector. Five separate spectra were acquired at different locations on each sample analysed. 
Exposure times were also varied in a set of experiments on the graphene oxide sample to study the changes caused by prolonged laser exposure. Five separate spectra were acquired at the same location on the graphene oxide sample using 1 second exposures, following this the location was submitted to 60 seconds of laser exposure before 5 repeat spectra were reacquired using 2 second exposures. This procedure of 60 seconds of unrecorded exposure followed by acquisition of five spectra was repeated a number of times. The total laser exposure time on this location was estimated and used to label each set of 5 spectra.

\subsection{Peak assignment and data processing methodology}

\subsubsection{Routine data processing procedure}

- Each spectrum was digitally smoothed using a $15 \mathrm{~cm}^{-1}$ moving mean (also known as a boxcar average) before measuring the parameters.

- D band position was measured at the maximum intensity between $1260 \mathrm{~cm}^{-1}$ and 1360 $\mathrm{cm}^{-1}$.

- D band height $\left(I_{D}\right)$ was measured as the maximum intensity between $1260 \mathrm{~cm}^{-1}$ and $1360 \mathrm{~cm}^{-1}$

- Valley height $\left(\mathrm{I}_{\mathrm{V}}\right)$ was measured as the minimum intensity between $1450 \mathrm{~cm}^{-1}$ and $1500 \mathrm{~cm}^{-1}$.

- $\mathrm{G}$ band position was measured at the maximum intensity between $1550 \mathrm{~cm}^{-1}$ and 1650 $\mathrm{cm}^{-1}$

- $\mathrm{G}$ band height $\left(\mathrm{I}_{\mathrm{G}}\right)$ was measured as the maximum intensity between $1550 \mathrm{~cm}^{-1}$ and $1650 \mathrm{~cm}^{-1}$. 
- A band position was measured at the maximum intensity between $1400 \mathrm{~cm}^{-1}$ and 1470 $\mathrm{cm}^{-1}$.

- A band height $\left(\mathrm{I}_{\mathrm{A}}\right)$ was measured as the maximum intensity between $1400 \mathrm{~cm}^{-1}$ and $1470 \mathrm{~cm}^{-1}$.

- A baseline value was obtained as the mean intensity between $400 \mathrm{~cm}^{-1}$ and $900 \mathrm{~cm}^{-1}$ and this baseline value was subtracted from $I_{D}, I_{V}, I_{A}$ and $I_{G}$ values before $I_{D} / I_{G}, I_{A} /$ $\mathrm{I}_{\mathrm{G}}$, and $\mathrm{I}_{\mathrm{V}} / \mathrm{I}_{\mathrm{G}}$ height intensity ratios were calculated.

- Additional ratios were calculated as $\left(\mathrm{I}_{\mathrm{D}}-\mathrm{I}_{\mathrm{V}}\right) /\left(\mathrm{I}_{\mathrm{G}}-\mathrm{I}_{\mathrm{V}}\right)$ and $\left(\mathrm{I}_{\mathrm{A}}-\mathrm{I}_{\mathrm{V}}\right) /\left(\mathrm{I}_{\mathrm{G}}-\mathrm{I}_{\mathrm{V}}\right)$ which each represented maximum height ratios of two peaks above the valley floor.

- In the event that the sharp ( 1 to $3 \mathrm{~cm}^{-1}$ wide) and intense spikes (attributed to "cosmic rays" striking the detector) happened to occur in a region of spectrum where they obviously interfered with how a parameter was measured, then a replacement spectrum was acquired from the sample or the 1 to $3 \mathrm{~cm}^{-1}$ worth of intense spike data was deleted to eliminate the spike's interference.

- From the five replicate spectra acquired at different locations on each sample, $99 \%$ confidence intervals were calculated assuming a normal distribution.

\subsubsection{Modified "photoluminescence slope" data processing procedure}

The previous routine procedure was applied with the following changes:

- A photoluminescence background slope was calculated using a linear regression through the data points on the smoothed spectra between $700 \mathrm{~cm}^{-1}$ and $2000 \mathrm{~cm}^{-1}$, while excluding all the data points between $1000 \mathrm{~cm}^{-1}$ and $1700 \mathrm{~cm}^{-1}$. This approach was adapted from a method reported by Casiraghia et. al. for the Raman analysis of hydrogenated amorphous carbon films [24]. 
- The photoluminescence background slope was subtracted from the smoothed spectrum.

- $\mathrm{G}$ band position was measured at the maximum intensity between $1500 \mathrm{~cm}^{-1}$ and 1650 $\mathrm{cm}^{-1}$.

- $\mathrm{G}$ band height $\left(\mathrm{I}_{\mathrm{G}}\right)$ was measured as the maximum intensity between $1500 \mathrm{~cm}^{-1}$ and $1650 \mathrm{~cm}^{-1}$.

- The slope of the photoluminescence background line was divided by the baseline corrected and photoluminescence subtracted $\mathrm{G}$ band height $\left(\mathrm{I}_{\mathrm{G}}\right)$ and then multiplied by $10,000 \mu \mathrm{m} / \mathrm{cm}$ to give a value in $\mu \mathrm{m}$. This parameter was based on a parameter that has been reported by Casiraghia et. al. which was previously applied in the Raman analysis of hydrogenated amorphous carbon films [24].

- The rest of the parameters were then measured and calculated from the "photoluminescence slope" corrected spectrum in the same way as described in the routine data processing procedure. This data processing procedure is demonstrated in Fig. 1. 


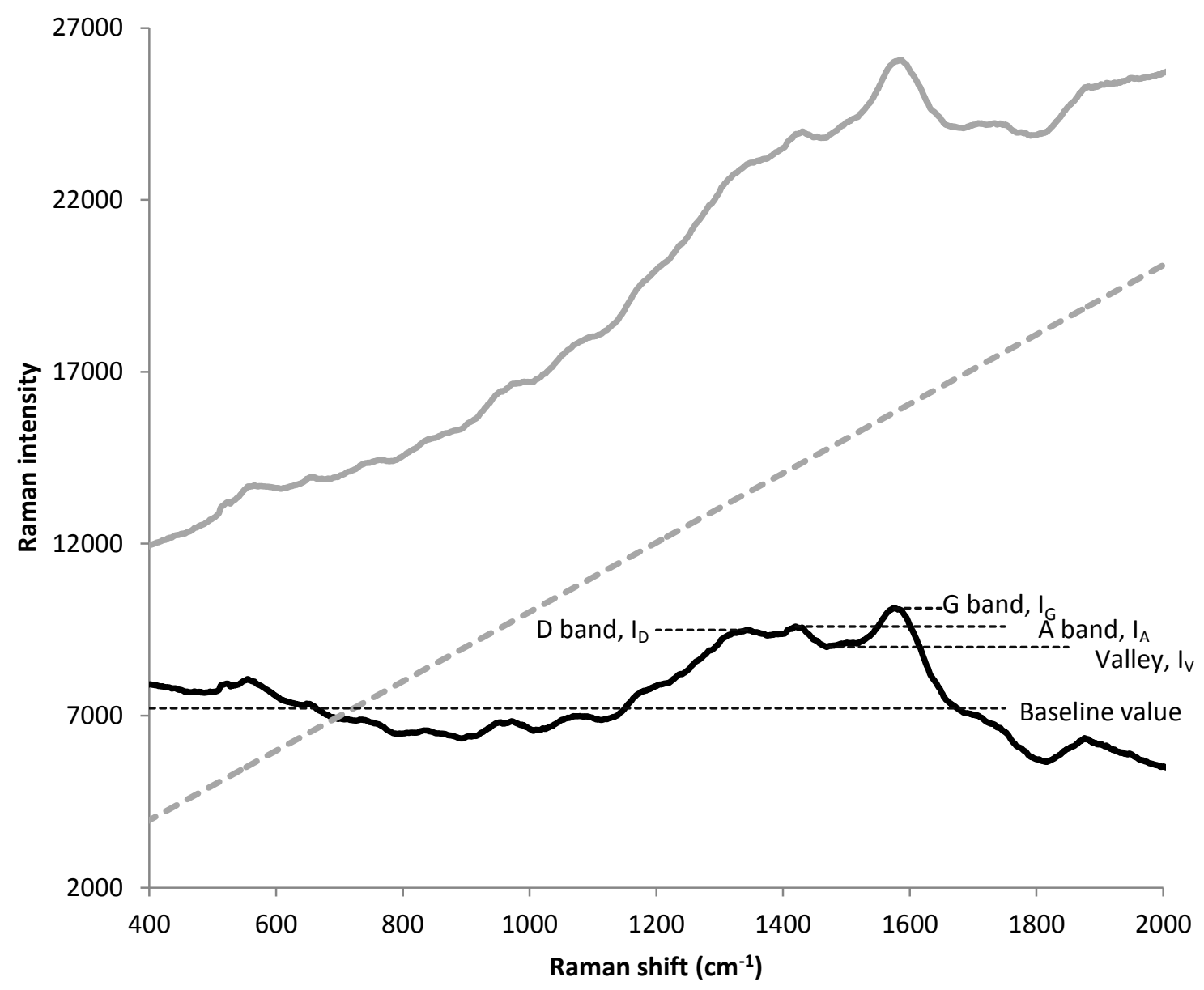

Fig. 1: Demonstration of a data processing procedure used to measure parameters. A spectrum obtained from a $\mathrm{HTT} \approx 550^{\circ} \mathrm{C}$ sucrose-derived char is displayed as these partially carbonised chars feature both “amorphous" and “graphene-like” $1^{\text {st }}$ order Raman signals. Grey spectrum is the original spectrum after the $15 \mathrm{~cm}^{-1}$ moving mean smoothing. Dotted grey line represents the calculated "photoluminescence" slope which is then subtracted from the grey spectrum to produce the black spectrum from which the parameters are measured in this modified data processing procedure. 


\section{Results and discussion}

\subsection{Development of routine methodology}

Laser induced heating of carbonaceous samples is known to redshift the position of the G band [25-27]. In order to assess the influence of laser heating on $\mathrm{G}$ band position on this particular instrument, two carbonaceous samples were analysed at different laser power settings. A sample of colloidal graphite which was dried onto a flat metal disk and a sample of radiata pine char $\left(\mathrm{HTT} \approx 470{ }^{\circ} \mathrm{C}\right)$ were chosen because they both possessed large flat surfaces onto which the laser spot could be focused and they also provided sufficient signal at lower laser power settings. The lower HTT pine char was expected to be significantly less thermally conductive compared to the sample of graphite on metal. Trials found that increasing the laser power to $20 \%$ might redshift the $\mathrm{G}$ band by $1-2 \mathrm{~cm}^{-1}$ which was within the typical variation when these carbonaceous samples were re-analysed 5 times at the same laser power setting. A more significant redshift occurs when laser power was increased to $30 \%$ of maximum in the case of the pine char. A $100 \%$ laser power setting (estimated to be $\approx$ $3 \times 10^{6} \mathrm{~W} / \mathrm{m}^{2}$ ) was found to burn a visible hole in the pine char, and significantly redshifted the graphite sample's G band. The $20 \%$ laser power setting (estimated to be $\approx 6 \times 10^{5} \mathrm{~W} / \mathrm{m}^{2}$ ) was chosen for routine analysis as it was a compromise which reduced heating induced redshift to a value close to the resolution of the spectrometer, yet allowed sufficient signal to be rapidly acquired from the uneven surfaces typical of most materials analysed. 
Both Zickler et. al. and Sadezky et. al. have covered many of the issues and complications with extracting parameter values from the Raman spectra of carbonaceous materials. They highlight the general ambiguous nature of much of the literature and demonstrate that data processing choices such as the number of curves employed in deconvolution/curve-fitting processes can considerably change the parameter values obtained [10, 28]. Because of these complications and in some cases the arbitrary assignment and measurement of many Raman signals across the literature, the current data processing methodology is intended to be as simple, clear, and reproducible as possible. The methodology employed in this current study is probably most similar to one previously employed in a study of coal chars and metallurgical cokes [29], as it uses band heights instead of band areas and measures the height of the valley between the D and G bands as an indicator of amorphous carbon content. Other literature has informed the assignment of these parameters and this will be covered as these various Raman spectral features are discussed individually.

The use of assumptions and arbitrary assignments in data processing procedures for measuring parameters from the Raman spectra of disordered carbonaceous materials is somewhat inevitable. However, is important to detail the assumptions which were used, define what exactly is being measured for each spectral parameter, and maintain consistency in data processing procedures between samples in order to compare the values obtained. It must be always remembered that direct comparison of spectral parameter values requires that the same data processing procedure is applied to obtain those values, and this concept has been stressed by Quirico et. al.[30]. In addition the data processing procedure in the current work was developed around where dispersive signals appear when a $785 \mathrm{~nm}$ excitation laser is employed so further modification and general caution would be required for its use with other excitation wavelengths. 
The well-documented $1^{\text {st }}$ order, $\mathrm{sp}^{2}$-carbon-related bands which occur between $1100 \mathrm{~cm}^{-1}$ and $1700 \mathrm{~cm}^{-1}[10,22,27,28,30-33]$ were the main focus of this current data processing procedure. This was because these signals are generally the most intense and reliably detected in a wide range of samples using this instrument and have reasonably well-established assignments in the existing literature. While this approach appears suitable for monitoring the nanostructural development of the $\mathrm{sp}^{2}$ carbon-rich domains, it is less suitable for the spectra of samples where a more molecular approach to analysing the spectra would usually be more appropriate (such as the regular fullerenes and some of the most amorphous chars and least reduced graphene oxide samples). However, this current work involves applying the same methodologies and data processing procedures across the widest range of carbonaceous samples for comparison even in cases where a few samples are near the limits of this particular approach. Observations of other bands such as $2^{\text {nd }}$ order bands and signals which might correspond to oxygen functional groups will be briefly mentioned in the discussion although they were not routinely measured by the current procedure.

The data processing procedure was modified to adapt the routine procedure both to cope with and to extract another potentially useful parameter from the rising background common to low HTT chars. This modification was based on photoluminescence-based slope parameters which have been previously used in Raman investigations of hydrogenated amorphous carbon films $[24,34]$ and can also be applied to spectra without any obvious photoluminescence. This modified data processing procedure also proved useful in studying the laser induced changes occurring in the graphene oxide sample during Raman analysis. 


\subsection{Raman spectra of chars and carbonised chars}

The Raman spectra obtained from the various chars changed as the HTT used to produce and carbonise these samples was increased. The spectra obtained from lower HTT chars featured a prominent rising slope. This rising slope is likely to be the florescence reported to be a common problem when analysing coals [30] or mildly pyrolysed lignocellulosic materials [9, 10], and/or a type of photoluminescence similar to that which has been previously reported to be a feature in the Raman spectra of hydrogenated amorphous carbon films [24, 34]. The other signals which appeared in the spectra of lower HTT char tended to be very broad and the modified data processing method, which subtracts this photoluminescence slope, was required to measure these signals. The change in overall appearance of the spectra as HTTs were increased was very similar across chars prepared from all three precursors (Fig. 2, Fig.

S1 and Fig S2, see Supplementary material). The signal located in the vicinity of $1590 \mathrm{~cm}^{-1}$, (measured as the G band) appeared to develop first followed by a signal around $1330 \mathrm{~cm}^{-1}$ (measured as the D band) which also became prominent as HTTs approached $\approx 700{ }^{\circ} \mathrm{C}$. However, the overall development of the sucrose-derived chars below about $700{ }^{\circ} \mathrm{C}$ appeared to lag behind the chars derived from the two lignocellulosic materials. 

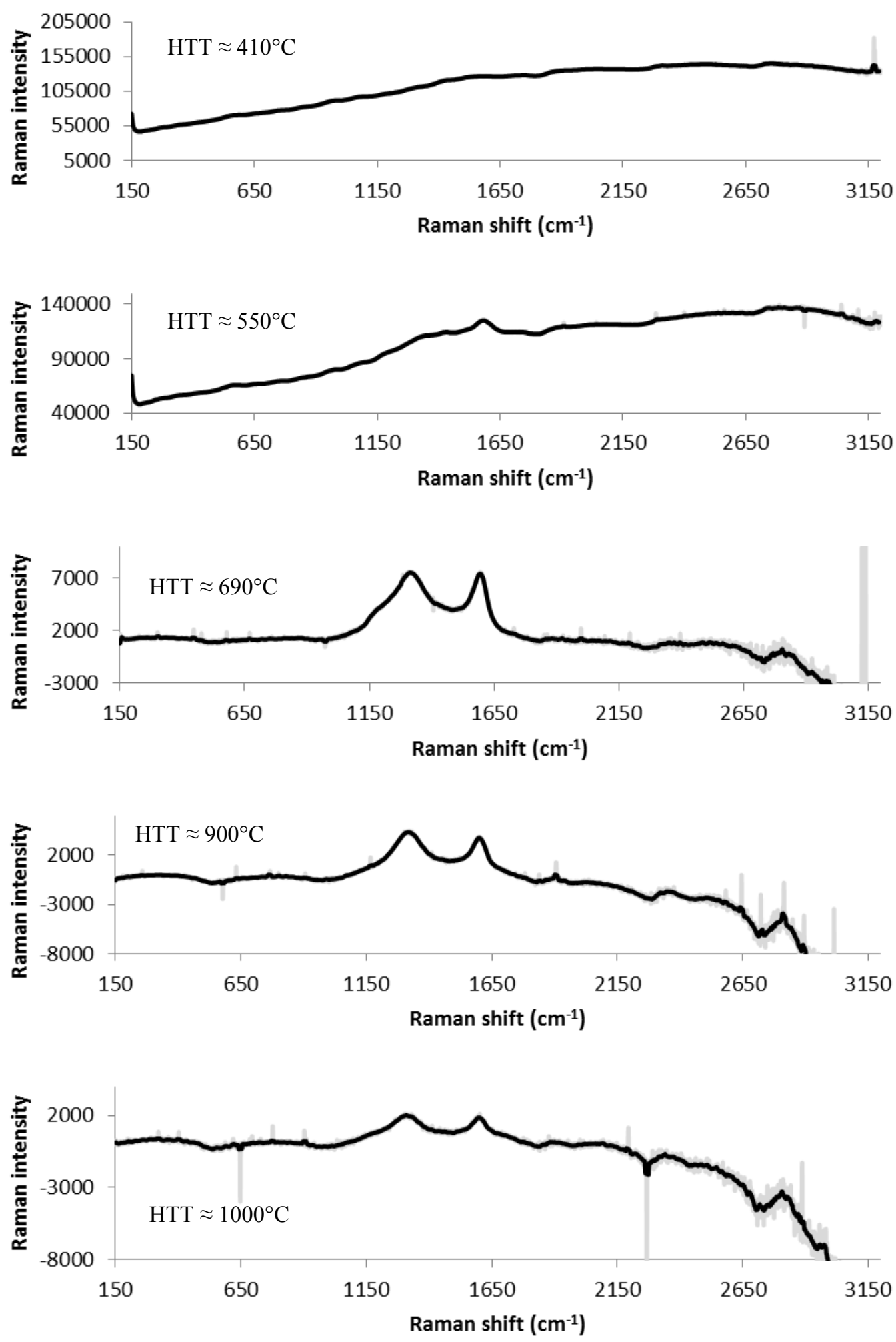

Fig. 2: Raman spectra of sucrose-derived chars produced at a range of HTTs. Grey line represents raw data (sum of 5 separate spectra) and black line represents $15 \mathrm{~cm}^{-1}$ smoothing of raw data using a moving mean. 


\subsection{Spectra of graphene oxides and thermally reduced graphene oxides}

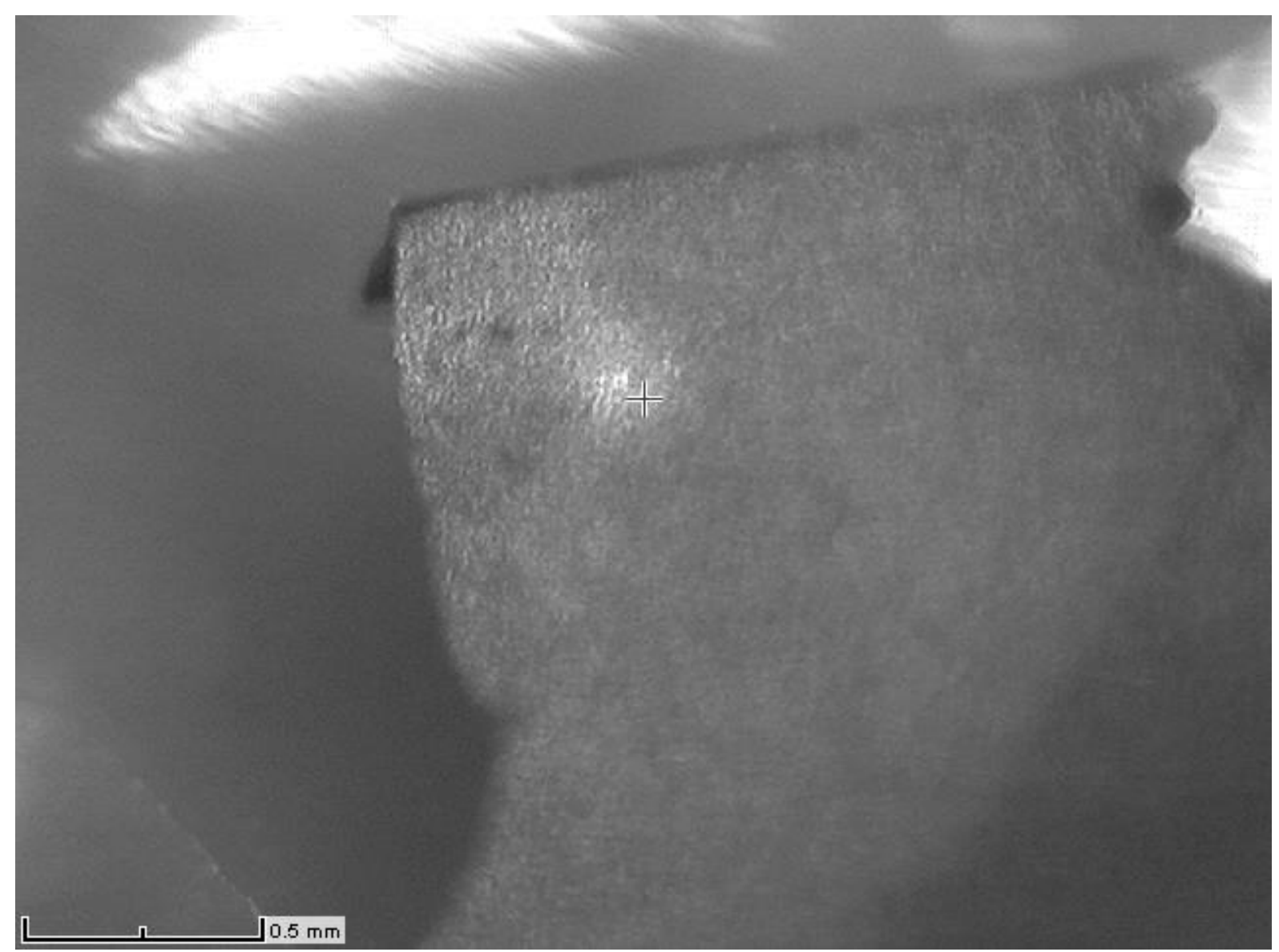

Fig. 3: Graphene oxide platelet sample. The cross represents the location where Raman analysis was carried out (20\% of maximum laser power, > 100 seconds of laser exposure). 
During initial attempts to acquire Raman spectra of the as-received graphene oxide platelets it was observed that the Raman spectrum was changing during the process of repeat analysis on the same location and following Raman laser exposure the surfaces had a silver-like metallic appearance (Fig. 3). This indicated that Raman laser exposure was actually partially reducing the graphene oxide during the analytical procedure. Intense light (both lasers and flash lamps) has previously been deliberately utilised to reduce graphene oxides $[19,35,36]$. This is a potential problem as it means that many spectra labelled as graphene oxide (in this current work and also in the existing graphene oxide literature) represent various types of "Raman laser reduced" graphene oxides instead. A series of spectra were acquired using increasing laser exposure times on a region of the graphene oxide sample to further investigate this observation. These spectra are displayed in Fig. 4, together with spectra of graphene oxide samples which were thermally-reduced in electric furnaces. This set of spectra provides an overview of the nanostructural development which occurs during the reduction of graphene oxide. The spectra acquired using $<6$ seconds of laser exposure are likely to be the closest to the "true" Raman spectrum of a "non-reduced" graphene oxide sample. This Raman spectrum lacks prominent graphene-like D and G band signals and is more similar to amorphous carbon materials (such as amorphous carbon thin films acquired using higher wavelength lasers $[22,37]$ and the very low HTT chars in Fig. 14). In this graphene oxide sample the G band appears to develop first during the reduction process and is followed by the development of a prominent $\mathrm{D}$ band in way that resembles what is seen in the carbonisation of chars. Eigler et. al. have recently used the term "structured" to describe graphene oxide samples modified by laser induced heating during (or prior to) Raman analysis which is likely to be related to the reduction process observed in Fig. 4. 

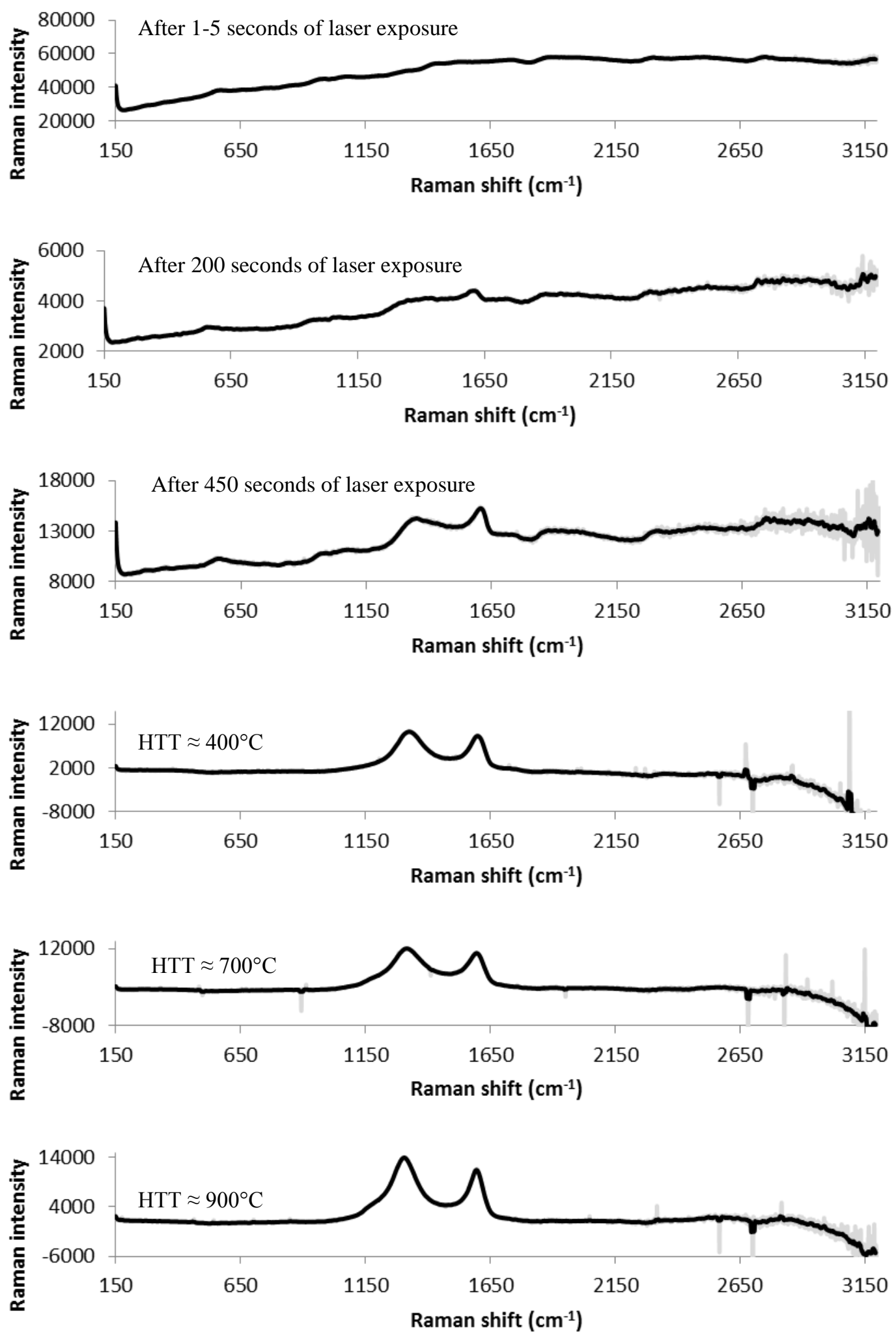

Fig. 4: Raman spectra of graphene oxide (after various durations of laser exposure) and thermally reduced graphene oxides prepared at various HTTs. Grey line represents raw data (sum of 5 separate spectra) and black line represents $15 \mathrm{~cm}^{-1}$ smoothing of raw data using a moving mean. 


\subsection{Spectra of other carbonaceous materials and nanostructures}
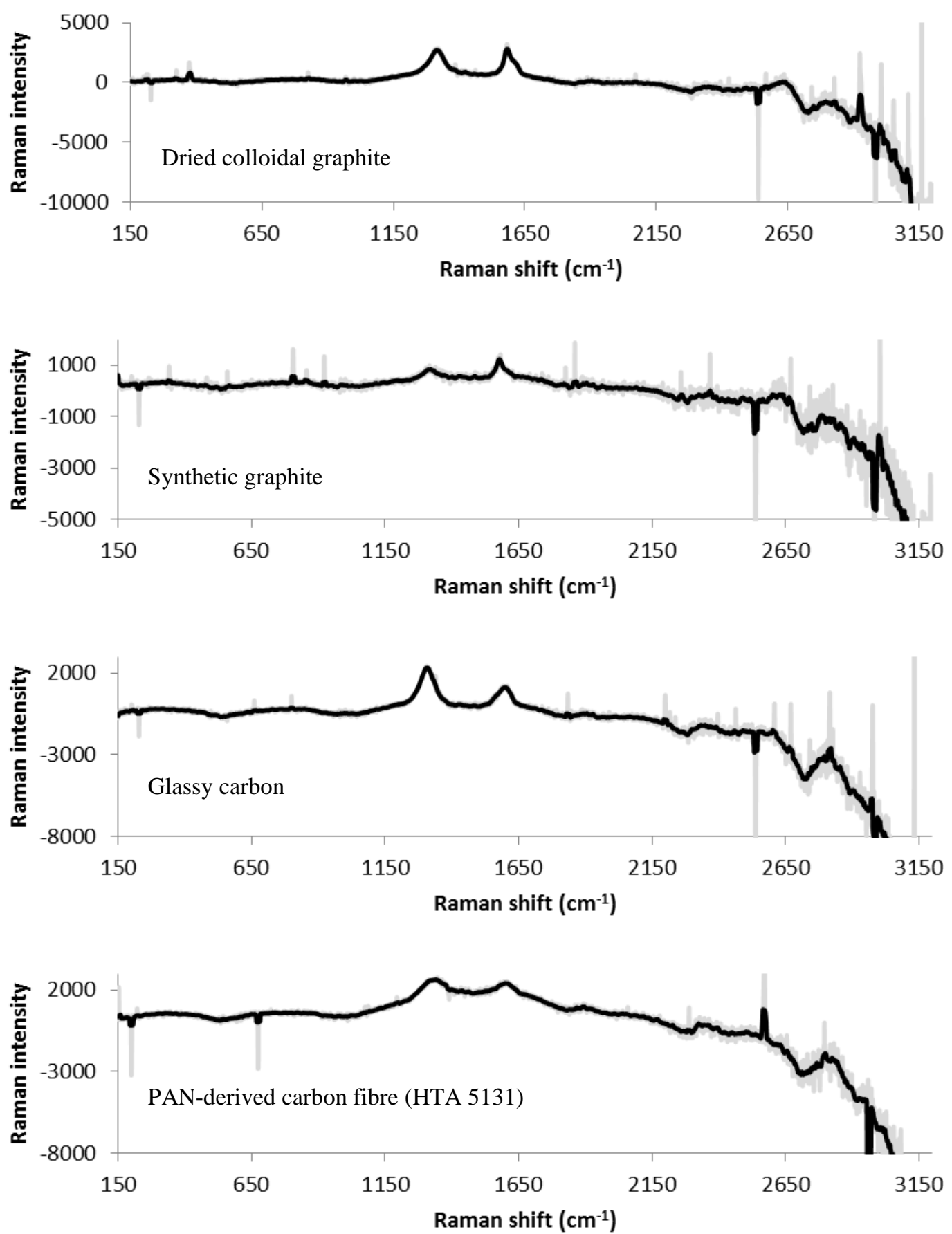

Fig. 5: Raman spectra of commercial samples of colloidal graphite, synthetic graphite, glassy carbon, and PAN-derived carbon fibre. Grey line represents raw data (sum of 5 separate spectra) and black line represents $15 \mathrm{~cm}^{-1}$ smoothing of raw data using a moving mean. 

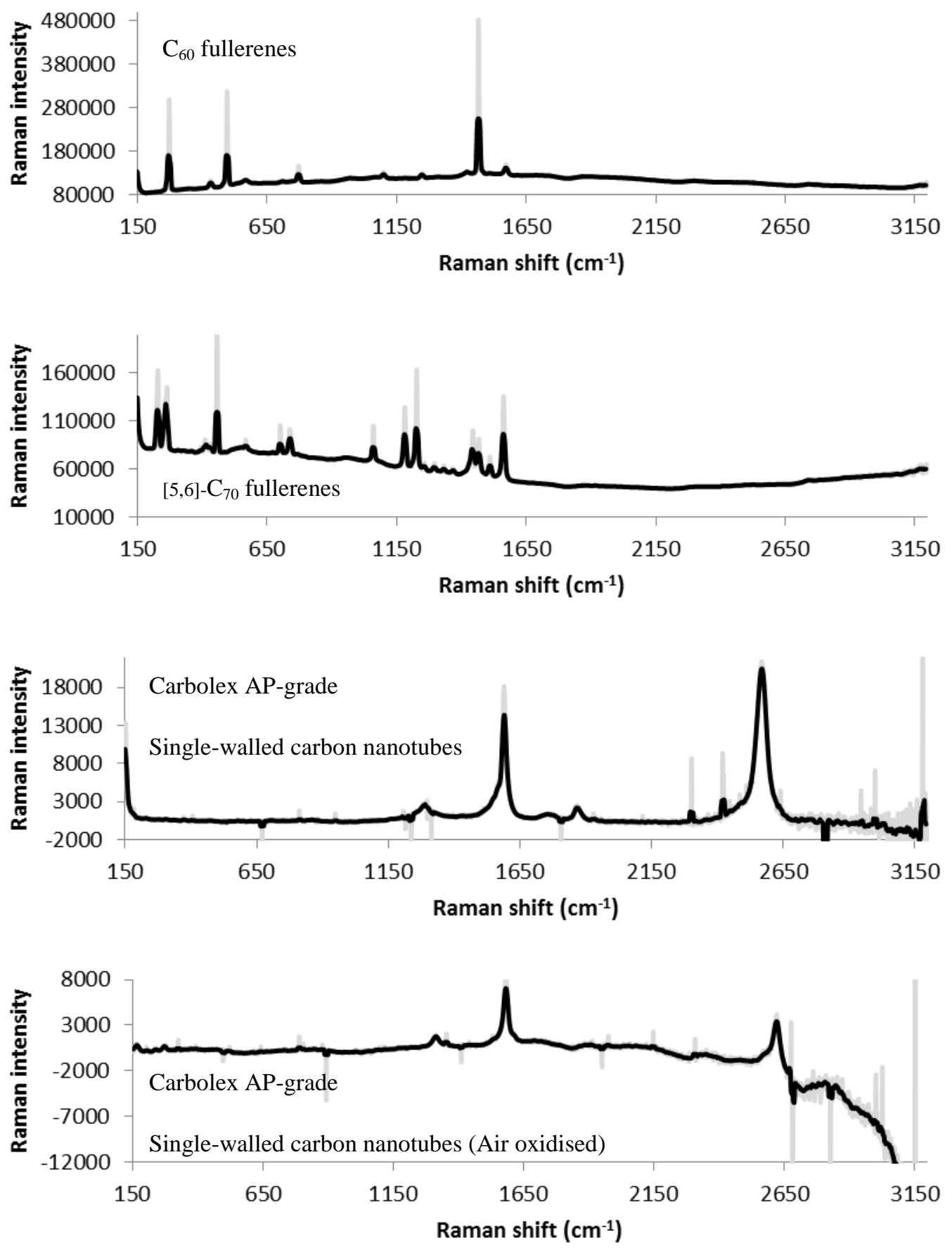

Fig. 6: Raman spectra of $\mathrm{C}_{60}$ fullerenes, [5,6]- $\mathrm{C}_{70}$ fullerenes, and single-walled carbon nanotubes. Grey line represents raw data (sum of 5 separate spectra) and black line represents $15 \mathrm{~cm}^{-1}$ smoothing of raw data using a moving mean. Note: this smoothing was probably not very appropriate for the fullerene spectra. 
Raman spectra were obtained from various commercial carbonaceous materials (Fig. 5), regular fullerenes and single-walled carbon nanotubes (Fig. 6) for valid comparison with the chars, carbonised chars and graphene oxide-derived materials when employing the same Raman instrument, methodology, and data processing procedure. The spectra of the glassy carbon, HTA type carbon fibres, and graphite samples appear consistent with typical spectra of these materials reported elsewhere [10, 38, 39]. The spectra of carbonised chars and thermally-reduced graphene oxide broadly resemble the spectra which were obtained from the dried colloidal graphite, glassy carbon and the sample of PAN-derived carbon fibre as they each feature two prominent signals between 1300 and $1620 \mathrm{~cm}^{-1}$. The $\mathrm{C}_{60}$ and $\mathrm{C}_{70}$ fullerenes have spectra with a number of narrow and intense signals, many of which have been reported and assigned in previous studies [40-42]. Some of these fullerene signals occur in positions similar to where the two prominent signals typical of the other carbonaceous materials occur; however many have no obvious corresponding signals in the spectra of the other carbonaceous materials. The spectra recorded for the as-received single-walled carbon nanotube (SWCNT) samples were consistent with spectra of this brand of SWCNT reported elsewhere with prominent signals typically assigned as the $\mathrm{G}^{\prime}$ band $\left(\approx 2570 \mathrm{~cm}^{-1}\right), \mathrm{G}$ band $(\approx$ $\left.1590 \mathrm{~cm}^{-1}\right)$, and D band $\left(\approx 1290 \mathrm{~cm}^{-1}\right)$ [39]. The spectra recorded from the sample of SWCNT treated with air oxidation still resembled the as-received SWCNT spectra more than any other carbonaceous material analysed so far. However, a number of changes can be observed in the Raman spectra of the SWCNT sample following this oxidation treatment, including the reduction in intensity of the signal near $2600 \mathrm{~cm}^{-1}$ ( $\mathrm{G}^{\prime}$ band) and the significant blueshifting or redshifting of many prominent signals. 
Throughout this work the term "glassy carbon" is used to refer to the commercial sample used as a "standard" in this Raman analysis. There are technical reasons why the very common terms "glassy carbon" and "glass-like carbon" should not be used to describe this material [21]. These terms imply that the nanostructure is "glass-like" and "amorphous" which is incorrect and misleading when this material is considered to actually consist of (almost entirely $\mathrm{sp}^{2}$-bonded) warped graphene-like sheets (with a high degree of two dimensional order) as turbostratic stacks $[2,38]$ forming what is described as an agranular, non-graphitisable structure (at lengths greater than $\approx 10 \mathrm{~nm}$ ) with high isotropy in most properties [21]. 


\subsection{Spectral parameter measurements and their interpretation}

Table 1: Measured values for $G$ band and $D$ band positions

\begin{tabular}{|c|c|c|c|c|c|c|}
\hline \multirow[b]{2}{*}{$\mathrm{C}_{60}$ Fullerenes $^{1}$} & \multicolumn{3}{|c|}{ G band position $\left(\mathrm{cm}^{-1}\right)$} & \multicolumn{3}{|c|}{ D band position $\left(\mathrm{cm}^{-1}\right)$} \\
\hline & 1571.8 & \pm & 1.0 & 1340 & \pm & 95 \\
\hline \multirow[t]{4}{*}{$\mathrm{C}_{70}$ Fullerenes $^{2}$} & 1562.0 & \pm & 1.0 & 1295.0 & \pm & 1.0 \\
\hline & & & & 1258.0 & \pm & 1.0 \\
\hline & & & & 1331.0 & \pm & 1.0 \\
\hline & & & & 1368.0 & \pm & 1.0 \\
\hline Dried Colloidal Graphite & 1583.2 & \pm & 0.5 & 1316.4 & \pm & 3.2 \\
\hline Synthetic Graphite & 1578.4 & \pm & 1.7 & 1316.2 & \pm & 6.8 \\
\hline Synthetic Graphite (Air oxidised) & 1580.0 & \pm & 2.0 & 1319.4 & \pm & 3.0 \\
\hline Single-Walled Carbon Nanotubes & 1590.6 & \pm & 1.0 & 1289.6 & \pm & 0.6 \\
\hline Single-Walled Carbon Nanotubes (Air oxidised) & 1581.8 & \pm & 0.5 & 1314.0 & \pm & 1.4 \\
\hline Glassy Carbon & 1598.8 & \pm & 2.5 & 1308.8 & \pm & 2.6 \\
\hline PAN Carbon Fibres (Tenax HTA5131) & 1601.2 & \pm & 1.0 & 1328.2 & \pm & 3.3 \\
\hline Graphene Oxide (after 1-5 seconds of laser exposure)*1 & 1508.2 & \pm & 3.0 & 1331 & \pm & 30 \\
\hline Graphene Oxide (after $\approx 200$ seconds of laser exposure)* & 1601.6 & \pm & 7.7 & 1345.0 & \pm & 3.8 \\
\hline Graphene Oxide (after $\approx \mathbf{4 5 0}$ seconds of laser exposure)* & 1606.4 & \pm & 1.0 & 1347.8 & \pm & 7.5 \\
\hline Thermally-reduced Graphene Oxide $400{ }^{\circ} \mathrm{C}$ & 1597.0 & \pm & 2.0 & 1324.8 & \pm & 3.5 \\
\hline Thermally-reduced Graphene Oxide $700{ }^{\circ} \mathrm{C}$ & 1594.8 & \pm & 2.1 & 1316.8 & \pm & 3.9 \\
\hline Thermally-reduced Graphene Oxide $900{ }^{\circ} \mathrm{C}$ & 1593.8 & \pm & 1.5 & 1307.6 & \pm & 4.4 \\
\hline Harakeke Char $430{ }^{\circ} \mathrm{C}$ & 1576.8 & \pm & 3.5 & 1351.0 & \pm & 7.9 \\
\hline Harakeke Char $550{ }^{\circ} \mathrm{C}$ & 1583.8 & \pm & 1.3 & 1329.6 & \pm & 3.3 \\
\hline Harakeke Char $700^{\circ} \mathrm{C}$ & 1593.8 & \pm & 1.5 & 1321.2 & \pm & 2.6 \\
\hline Harakeke Char $900^{\circ} \mathrm{C}$ & 1595.6 & \pm & 1.9 & 1312.8 & \pm & 6.3 \\
\hline Harakeke Char $1000{ }^{\circ} \mathrm{C}$ & 1596.8 & \pm & 2.8 & 1307.0 & \pm & 1.6 \\
\hline Sucrose Char $410^{\circ} \mathrm{C}^{1}$ & 1512 & \pm & 10 & 1350 & \pm & 22 \\
\hline Sucrose Char $550{ }^{\circ} \mathrm{C}$ & 1582.4 & \pm & 6.2 & 1355.4 & \pm & 6.1 \\
\hline Sucrose Char $700{ }^{\circ} \mathrm{C}$ & 1593.4 & \pm & 1.7 & 1315.0 & \pm & 5.7 \\
\hline Sucrose Char $900{ }^{\circ} \mathrm{C}$ & 1600.4 & \pm & 1.3 & 1317.0 & \pm & 7.1 \\
\hline Sucrose Char $1000^{\circ} \mathrm{C}$ & 1599.0 & \pm & 1.6 & 1309.0 & \pm & 2.9 \\
\hline Radiata Pine Char $340{ }^{\circ} \mathrm{C}^{* 1}$ & 1510.6 & \pm & 6.8 & 1320 & \pm & 26 \\
\hline Radiata Pine Char $470{ }^{\circ} \mathrm{C}$ & 1576.4 & \pm & 1.7 & 1348.2 & \pm & 6.3 \\
\hline Radiata Pine Char $700{ }^{\circ} \mathrm{C}$ & 1591.8 & \pm & 1.5 & 1317.8 & \pm & 1.7 \\
\hline Radiata Pine Char $1000{ }^{\circ} \mathrm{C}$ & 1599.0 & \pm & 2.9 & 1308.8 & \pm & 3.0 \\
\hline \multicolumn{7}{|c|}{ Values with \pm representing $99 \%$ confidence intervals calculated from 5 sub-samples and assuming a normal distribution } \\
\hline \multicolumn{7}{|c|}{ *Measured using photoluminescence-based modified data processing procedure. Spectra for graphene oxide samples were repeated } \\
\hline \multicolumn{7}{|c|}{ acquired from the same location to demonstrate the way increasing laser exposure changed the structure of graphene oxide. } \\
\hline \multicolumn{7}{|l|}{${ }^{1}$ No $\mathrm{D}$ band able to be reliably distinguished. } \\
\hline${ }^{2}$ Potential "D band" signals measured manually as they a & nilar in & & & & & \\
\hline
\end{tabular}




\subsubsection{G band position}

The chars and carbonised chars analysed appeared to have $\mathrm{G}$ band positions which increased (blueshifted) towards $1600 \mathrm{~cm}^{-1}$ as the HTTs used to produce them were increased towards $1000{ }^{\circ} \mathrm{C}$ as demonstrated in Fig. 7. This general trend of increasing $\mathrm{G}$ band position with increasing HTT has previously been reported for Japanese cedar wood and bark [9].

However, Raman studies on sets of chars produced from pyrolysing European spruce wood did not report as clear or significant correlations between HTT and G band positions [10, 43], which could be due to differences in Raman instruments, data processing methodologies, or possibly in char production heating rates across the various studies.

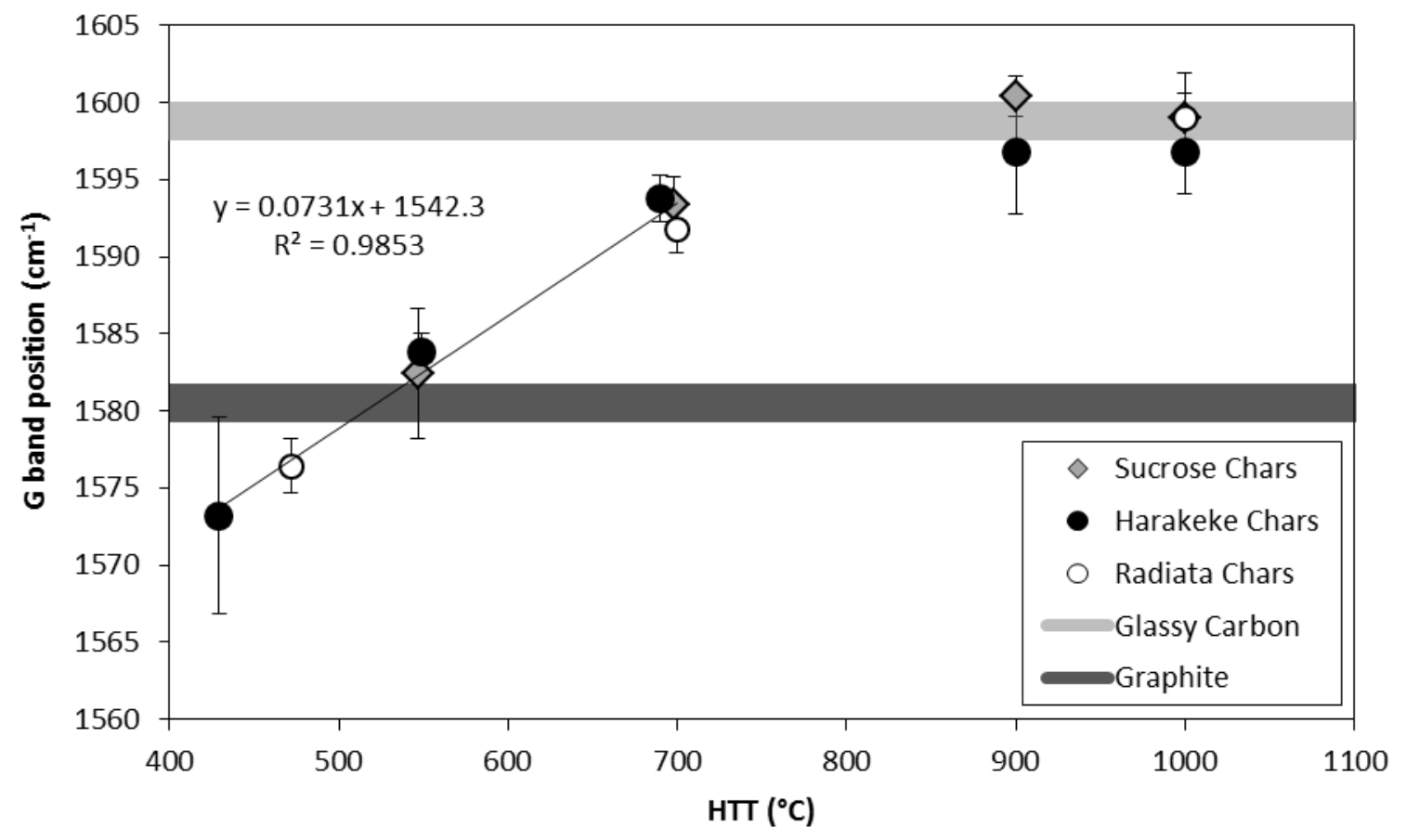

Fig. 7: Plot of $G$ band position as a function of heat treatment temperature for chars.

Broad horizontal guide lines represent approximate $G$ band positions measured for glassy carbon and graphite samples. Linear trend line and correlation based on mean data points (from chars derived from all three precursors) between HTT $\approx 420{ }^{\circ} \mathrm{C}$ and HTT $\approx 700{ }^{\circ} \mathrm{C}$. 
The $\mathrm{G}$ band positions measured for lower HTT chars prepared between HTTs of $\approx 470{ }^{\circ} \mathrm{C}$ and $\approx 550{ }^{\circ} \mathrm{C}$ are not significantly different from those measured for the various graphite samples (Table 1). In contrast, the chars carbonised at higher HTTs $\left(\approx 700{ }^{\circ} \mathrm{C}\right.$ to $\left.\approx 1000{ }^{\circ} \mathrm{C}\right)$, had $\mathrm{G}$ band positions closer to those measured for samples of PAN carbon fibres, glassy carbon, and thermally-reduced graphene oxide samples. These $\mathrm{G}$ band positions closer to $1600 \mathrm{~cm}^{-1}$, are similar to what has been previously reported for nanocrystalline graphites [22], certain lower modulus carbon fibres [26, 33, 44], and glassy carbons [38]. Aromatic clusters are considered to grow larger and more graphene-like as the HTTs increase [7, 8, 43] and the observation of the $\mathrm{G}$ band position moving away from the position near $1580 \mathrm{~cm}^{-1}$ typical of graphite as HTTs are increased towards $900-1000{ }^{\circ} \mathrm{C}$, is difficult to explain without considering the possibility that this blueshift represents the nanostructure developing significant internal stress which puts the graphene-like networks under compressive strain. Evidence from a simpler model system which could support this concept can be found in studies on the Raman G band's response to uniaxial compressive and tensile strains in cases of mechanically-exfoliated single-layer graphene sheets $[45,46]$. The $\mathrm{G}$ band blueshifting with increasing compressive strain has also been observed in graphites $[47,48]$. The blueshift of the $\mathrm{G}$ band during the carbonisation process (Table 1 and Fig. 7), might be due to the graphene-like networks in carbonising chars being put under increasing compressive strain as the clusters grow large enough to collide, impinge, and/or merge with neighbouring clusters within a somewhat confined volume. This would be consistent with the percolation model put forth by Nagle et. al. where conductive nano-clusters grow through an insulating phase (of amorphous carbon) to become large enough to contact neighbouring clusters over the HTT range of $600{ }^{\circ} \mathrm{C}$ to $800{ }^{\circ} \mathrm{C}$, causing a great increase in electrical conductivity of the chars [8]. If $\mathrm{G}$ band position is largely strain related, then the measurements in Table 1 are likely to 
only relate to some kind of average or most common level of strain on graphene-like structures, and broad $\mathrm{G}$ band signals might then represent different populations of carboncarbon bonds within the material being under varying levels of strain (potentially a range including both tensile and compressive strains).

The Raman G band, which is named after the signal that typically occurs around $1582 \mathrm{~cm}^{-1}$ in graphites, is often assigned to a lattice vibration (or phonon) with $\mathrm{E}_{2 \mathrm{~g}}$ symmetry which occurs within the plane of a hexagonal ring structure composed of $\mathrm{sp}^{2}$ carbon atoms involving the stretching of the carbon-carbon bonds within that ring structure. [10, 31, 40, 49-51]. All pairs of $\mathrm{sp}^{2}$ bonded carbon atoms are thought to generate some kind of $\mathrm{G}$ band (including those in chains), however the wavenumber $\left(\mathrm{cm}^{-1}\right)$ positions at which they occur are often very different, as is the case with the various types of amorphous carbon $[22,31,38]$. The $\mathrm{G}$ band signal is known to occur in Raman spectra acquired from a wide range of carbonaceous materials including, cokes, chars, activated carbons, carbon fibres, carbon/furnace blacks, soot, coals, graphites and glassy carbons [33, 52]. Many carbon nanostructures also contain extensive network structures composed of $\mathrm{sp}^{2}$ carbon atoms, so a $\mathrm{G}$ band is found in the Raman spectra of carbon nanotubes (single and multi-walled), onion-like carbon, graphene sheets, and a multitude of other nanostructures considered to have graphene-like sheets as their building blocks $[32,52-54]$. Signals in the spectra of regular fullerenes $\left(\mathrm{C}_{60}\right.$ and $\left.\mathrm{C}_{70}\right)$ which appear reasonably close to the typical $\mathrm{G}$ band for graphene-like structures have been assigned as "G bands" in Table 1 due to the way the data processing procedure has measured them. Treating such signals as fullerene $\mathrm{G}$ bands has previously been a feature of research where the redshifted position of these fullerene $G$ bands (when compared to graphite $G$ bands) is interpreted as due to curvature induced tensile strain (and associated bond lengthening) [40, 54]. 
It has been previously established that $\mathrm{G}$ band position is dispersive (shifting with changes in the wavelength of the excitation laser employed in the Raman instrument) in cases of truly amorphous carbon with significant proportions of both $\mathrm{sp}^{2}$ and $\mathrm{sp}^{3}$ bonded material $[22,55]$. An increase in the dispersive behaviour of the $\mathrm{G}$ band's position is strongly associated with increased disorder of the carbon [22]. Based upon results and dispersive trends reported by Ferrari and Robertson [22] and assuming that these trends continue into near-infrared, it can be estimated that when using an excitation wavelength of $785 \mathrm{~nm}$ tetrahedral amorphous carbon $\left(\right.$ ta- $\left.\mathrm{C}, \approx 85 \% \mathrm{sp}^{3}\right)$ has a $\mathrm{G}$ band position close to $1440 \mathrm{~cm}^{-1}$, amorphous carbon $(\mathrm{a}-\mathrm{C}, \approx$ $20 \% \mathrm{sp}^{3}$ ) has a $\mathrm{G}$ band position close to $1530 \mathrm{~cm}^{-1}$, and hydrogenated tetrahedral amorphous carbon (ta-C:H, $\approx 50 \% \mathrm{sp}^{3}$ ) has a $\mathrm{G}$ band position close to $1460 \mathrm{~cm}^{-1}$. This means that although it is best to study these amorphous carbons and so-called "diamond-like" carbons using a range of excitation laser wavelengths to evaluate their dispersive behaviour [22], the $785 \mathrm{~nm}$ excitation laser featured on the Raman instrument used in the current work should greatly redshift most amorphous carbon $\mathrm{G}$ bands away from the $\mathrm{G}$ band positions (near 1580 $\mathrm{cm}^{-1}$ ) typical of graphene-like and graphite-like carbon. Thus, the greatly redshifted G band positions (near $1510 \mathrm{~cm}^{-1}$ ) measured for the lowest HTT chars and the graphene oxide sample analysed using the shortest exposure time (Table 1) could be interpreted as representing very small aromatic clusters (of a few hexagonal rings) surrounded by amorphous $\mathrm{sp}^{3}$-rich structures. G band positions (and widths) could also be influenced by other factors in cases of complex macromolecular structures, especially those featuring oxygen-containing functional groups such as chars and graphene-oxide derivatives. 
The changes in measured $\mathrm{G}$ band positions during the reduction of graphene oxide are different to those observed during the carbonisation of char. The least reduced graphene oxide sample (after 1-5 seconds of laser exposure) featured weak, broad G bands which are remarkably similar to those recorded for very low HTT chars (near $1510 \mathrm{~cm}^{-1}$ ) and suggests that both materials contain small aromatic clusters within an amorphous carbon structure which also contains a small quantity $(\approx 20 \%)$ of local $\mathrm{sp}^{3}$ bonding [22]. However, once a sharper graphene-like $\mathrm{G}$ band appears in the spectrum of mildly reduced graphene oxide (after $\approx 200$ seconds of laser exposure) it is at a greatly blueshifted position of $\approx 1600 \mathrm{~cm}^{-1}$. In contrast to the apparent $\mathrm{G}$ band blueshift observed during the carbonisation of chars, the continued reduction of this graphene oxide appears to cause a much smaller redshift in $\mathrm{G}$ band positions. If the interpretation of $\mathrm{G}$ band position being largely strain related is correct, then this observation can be explained as the graphene-like domains formed during this reduction of graphene oxide being initially under considerable compressive strain. This proposed compressive strain on the graphene-like domains could be caused by the confinement within a large network/sheet which is still greatly distorted by oxygen functional groups, $\mathrm{sp}^{3}$ bonding, and other defects, with the observed redshifting explained as indicating a partial relaxation of this strain caused by thermal annealing partially removing these defects. The contrasting steady blueshift of $\mathrm{G}$ band positions during the char carbonisation process, would then be explained as demonstrating that unlike graphene oxides, the graphenelike aromatic domains in chars do not begin the process as part of large covalent network/sheet structures, and instead these aromatic clusters grow and merge into large distorted "thermally-reduced-graphene-oxide-like" networks as they are exposed to more severe thermal treatments. 
A major concern when using $\mathrm{G}$ band positions involves the $\mathrm{D}^{\prime}$ band which is associated with disorder in graphene-like samples and typically occurs near $1620 \mathrm{~cm}^{-1}[10,27,56]$ and how this band may overlap and interfere to a potentially unknown degree with the G band. Only in spectra obtained from the dried colloidal graphite was a $\mathrm{D}^{\prime}$ band clearly observable as a distinct shoulder on the higher wavenumber side of the $\mathrm{G}$ band. The term "apparent $\mathrm{G}$ band position" might be more appropriate for the values displayed in Table 1, as it acknowledges the possibility that what is measured as the $\mathrm{G}$ band position could be heavily influenced by the position and intensity of a $\mathrm{D}^{\prime}$ band in many of the carbonaceous samples analysed. The use of "apparent G band position" measurements to estimate effective HTTs and evaluating the extent of carbonisation (Fig. 7) should still work if any D' band contribution is also HTT dependent in a reliable way. However, an unknown contribution from an overlapping $\mathrm{D}^{\prime}$ band will cast some doubt on the more detailed interpretations of $\mathrm{G}$ band position measurements. The observed blueshift in the $\mathrm{G}$ band could have other potential explanations. It might simply be a common feature of polyaromatic (graphene-like) structures with coherent domains about 1-2 $\mathrm{nm}$ across as it has been previously reported that larger polycyclic aromatic hydrocarbon structures such as hexabenzocoronene have a $\mathrm{G}$ band closer to $1600 \mathrm{~cm}^{-1}$ [28]. 


\subsubsection{D band position}

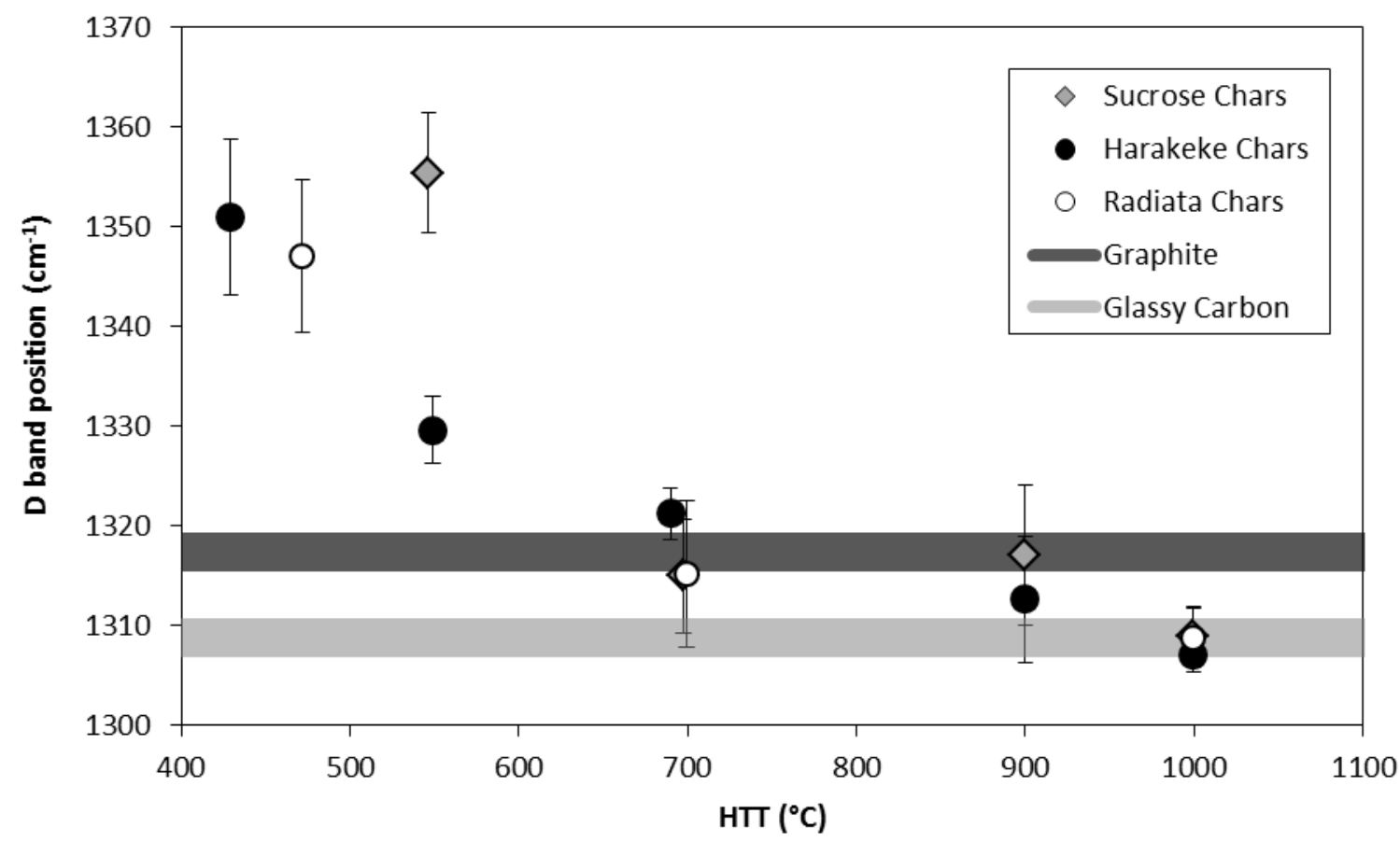

Fig. 8: Plot of $D$ band position as a function of heat treatment temperature for chars.

Broad guide lines represent approximate $D$ band positions measured for glassy carbon and graphite samples. 
The process of carbonising harakeke leaf fibres, sucrose crystals, and radiata pine wood caused D band positions to redshift towards $1308 \mathrm{~cm}^{-1}$ as the HTTs increased towards 1000 ${ }^{\circ} \mathrm{C}$ (Fig. 8). These results are similar to the trend of decreasing D band position with increasing HTT, previously reported for chars produced from Japanese cedar wood and bark [9]. Adjusting those values reported for Japanese cedar chars [9] for laser related dispersion [31], leads to D band position values which are a close match to those found for chars analysed in this current work. Previous Raman analysis on sets of chars produced from pyrolysing European spruce wood reported a 3-4\% redshift in D band position as the HTTs were increased towards $\approx 800{ }^{\circ} \mathrm{C}[43]$ which is similar to the results in Table 1 . In contrast, results from another study featuring Raman analysis on European spruce wood did not demonstrate clear trends in D band position change with increasing HTTs below $1000{ }^{\circ} \mathrm{C}$ [10]. Zickler et. al. did however, demonstrate that changes to the curve fitting methodology made a very significant difference to D band values obtained below $1000{ }^{\circ} \mathrm{C}[10]$, which might account for their unusual sets of D band values. 
The $\mathrm{D}$ band position measurements for the diverse range of samples analysed using this Raman instrument and data processing procedure are summarised in Table 1.The Raman D band is named after disorder and its appearance in a spectrum is commonly attributed to the presence defects and/or edges in graphene-like structures. The D band is dispersive and this band's excitation wavelength dependent position (and relative intensity) has been well studied in graphene-based, carbonaceous materials [56, 57]. All pairs of $\mathrm{sp}^{2}$ bonded carbon atoms are thought to generate $\mathrm{G}$ bands including those in chains, however because it is related to ring breathing modes, only hexagonal aromatic rings are understood to generate a $\mathrm{D}$ band and only when the ring is in close proximity (within $\approx 4 \mathrm{~nm}$ ) to an edge or other defect $[22,31,32]$. When large highly-ordered graphite crystals (and large pristine graphene monolayers) are analysed using a laser spots small enough to avoid any edges, no D band is observed [56, 58]. Despite the well-established association of the D band with defects and disorder, the appearance of this signal does appear to require ordered graphene-like domains (larger than about $0.5 \mathrm{~nm}$ across) to be present. Although the minimum graphene-like domain/cluster size required for D band signal generation is not well defined it has been depicted and discussed as being about 6 hexagonal rings fused together in a condensed aromatic network, meaning that $\mathrm{D}$ band generating carbon structures are considered to be highly ordered (usually at a nanometre scale) when compared to other truly amorphous forms of carbon $[22,59,60]$. 


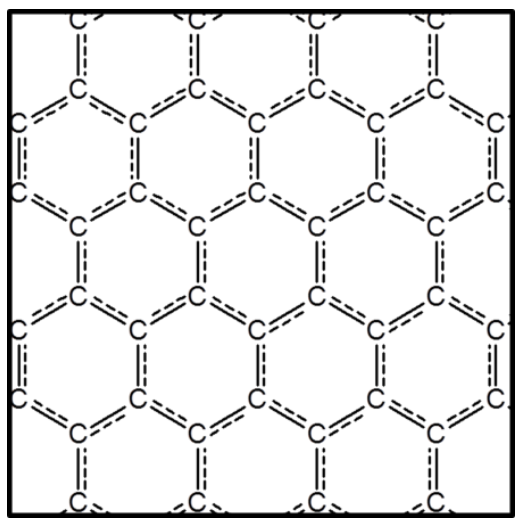

Fig. 9: Drawing of a graphene-like domain (depicted within a $\approx 1 \mathrm{~nm} \times 1 \mathrm{~nm}$ square) which indicates both the approximate size, extent of condensation, and the type of order referred to in discussions of this structural feature.

Raman results for the carbonaceous materials which produce abundant D band signal will generally be discussed and interpreted in terms of graphene-like domains being structural features similar to what is depicted in Fig. 9. The structure of the domain edges are intentionally not shown in Fig. 9 to emphasise that the edge of a coherent domain is not necessarily the termination of the covalent network (or even the end of a graphene-like sheet/layer [61]) and that the structures (and/or defects) which exist at the edge are liable to change significantly with increasing HTT. Because the traditional $1^{\text {st }}$ order Raman signals generally appear far more sensitive to covalent nanostructural features than to non-covalent inter-sheet stacking (graphitic, turbostratic or none/mono-layers) [31, 32, 62] the discussions in the current work will focus on structural changes within the covalent network. Thus the depiction in Fig. 9 deliberately excludes any details about how such domains might be stacked. 
The D band position generally redshifted during the process of thermally reducing the graphene oxide samples and like the carbonised chars it becomes redshifted towards (and in some cases significantly past) the D band positions measured for the various graphites. There is also a significant convergence of D band positions for all chars carbonised around 900$1000{ }^{\circ} \mathrm{C}$, the graphene oxides samples thermally reduced at $\approx 700-900{ }^{\circ} \mathrm{C}$, and the sample of glassy carbon. With $\mathrm{D}$ band positions around $1310 \mathrm{~cm}^{-1}$ these values are near the positions $(\approx$ $1316 \mathrm{~cm}^{-1}$ ) measured in various graphites and the SWCNTs treated with thermal air oxidation. If $\mathrm{D}$ band position provides information about near-edge structures, then this convergence would indicate that both carbonised chars and thermally-reduced graphene oxides develop near-edge structures which are similar to those found in glassy carbon and to a lesser extent graphites, suggesting that only a limited range of carbon edge/defect related structures can survive at these higher temperatures in limited oxygen environments. 
The $\mathrm{D}$ band position is often measured in Raman studies of carbonaceous materials $[9,10$, $17,33]$, however in most cases there has been no attempt to explain what changes in D band position correspond to, in regard to specific nanostructural features, edges, or other defects. This linking of $\mathrm{D}$ band signals to specific types of edges or defects is an area which has been identified as requiring further investigation [31, 32]. Based on the results in Table 1 and what has been previously report from other techniques analysing similar materials $[2,7,14,63$ 66], a tentative interpretation would be that these $\mathrm{D}$ band position values provide information about the most common types of edge and/or near-edge structures present around the graphene-like domains. The low HTT chars and "Raman-laser-reduced" graphene oxides presumably have aromatic clusters with edges/borders which feature predominately amorphous carbon ( $\mathrm{sp}^{3}$-bonded) structures, which leads to a D band positioned around 1350 $\mathrm{cm}^{-1}$. As $\mathrm{sp}^{3}$-bonded amorphous structures are removed with increasing temperatures the edges/defects could become more like those found in graphites or graphenes (presumably $\mathrm{sp}^{2}$ bonded edges terminated with radicals, hydrogen, and oxygen functional groups and/or various edge-reconstructions [67] including curved "nano-arches"[68]) which leads to a D band positioned around $1318 \mathrm{~cm}^{-1}$. As the HTT used to carbonise the char or anneal the thermally-reduced graphene oxide is increased towards $1000^{\circ} \mathrm{C}$, the curvature of the edges/distortions/defects could become much more prominent (and/or more "fullerenelike"[65]) which leads to D band positions closer to the $\approx 1308 \mathrm{~cm}^{-1}$ values obtained for the commercial glassy carbon sample. These ideas for interpreting D band positions in terms of near-edge structures will require further development and clarification, probably involving relating D band position directly to transmission electron microscope images, mathematical descriptions of curvature, and in-depth quantum mechanical modelling. Another consideration when attempting to interpret D band positions, involves studies on graphites 
under compression which appear to demonstrate that both the D band and the G band blueshift under compressive strains [47]. If D band position is also largely strain related then the results obtained (Table 1) would indicate that near-edge structures tend to be under more tensile strain than compressive strain as HTTs are increased towards $1000{ }^{\circ} \mathrm{C}$. This concept of most of the graphene-like components being under significant compressive strain, yet the curved graphene-like cross-links (near-edge/defect structures) being under more tensile strain would be broadly consistent with the kinds of structural models for non-graphitising carbons put forth by Franklin [11], Jenkins, and Kawamura [2], who all discuss the great internal stresses and strains which are considered to develop during the preparation of these materials. 
As indicated by extremely large $99 \%$ confidence interval in Table 1 , the spectra of $\mathrm{C}_{60}$ fullerenes featured no significant signals which could be measured as a D band using this particular data processing procedure. In contrast, the $\mathrm{C}_{70}$ fullerene spectra featured four distinct signals of similar intensity near the spectral region where they could potentially be measured as "D bands" by this type of data processing procedure. If these signals do represent some kind of embryonic D band equivalents generated by the asymmetric curvature present in these $\mathrm{C}_{70}$ fullerenes, then these bands could provide insight into how the $\mathrm{D}$ band behaves when "activated" by curvature (and pentagonal ring structures) which may in turn assist in interpreting the D bands present in more complex curved carbonaceous structures. The D band position measured for the as-received SWCNT sample was around $1290 \mathrm{~cm}^{-1}$ and is in agreement with results previously reported for this particular brand of SWCNTs analysed with $785 \mathrm{~nm}$ excitation [39] and consistent with $\approx 1.3 \mathrm{~nm}$ diameter SWCNTs according to an equation reported by Jorio et. al. [32]. The $1290 \mathrm{~cm}^{-1}$ value put this particular D band at a greatly redshifted position relative to graphite, but reasonably close to some of the $\mathrm{C}_{70}$ "D bands" (Table 1). Following the air oxidation treatment of a SWCNT sample, the D band was found to have significantly blueshifted to a position close to the positions measured for graphite samples. Single-walled carbon nanotubes are often described as having half fullerene end-caps, which are thought to be formed with vacuum annealing and removed with oxidative treatments $[14,69]$. D bands measured at positions which are redshifted when compared to graphite might represent more "fullerene-like" edge/defect structures. If this interpretation is correct, then the equation relating SWCNT diameters to D band positions [32], would only be applicable if the SWCNTs are capped with "fullerene-like" structures, as the equation may be more a measurement of the curvature/diameter of the "fullerene-like" edge/cap structures and not a direct measurement of the nanotube body diameter 
(presumably, smaller diameter nanotubes, when capped, will feature "fullerene-like" structures with smaller diameters and/or tighter curvatures). In these discussions the term "fullerene-like" is used to describe the kind of complex multiple-axis curvature of graphenelike structures which require the incorporation of non-hexagonal rings (especially, pentagons) as depicted by Harris et. al. $[14,65]$. This "fullerene-like" curvature is thus different from simpler curvature which does not require non-hexagonal rings and is common in the cylindrical body of SWCNTs and "nano-arches" which can occur on the edges of graphite crystals [68]. 


\subsubsection{D band and G band relative intensity ratios}

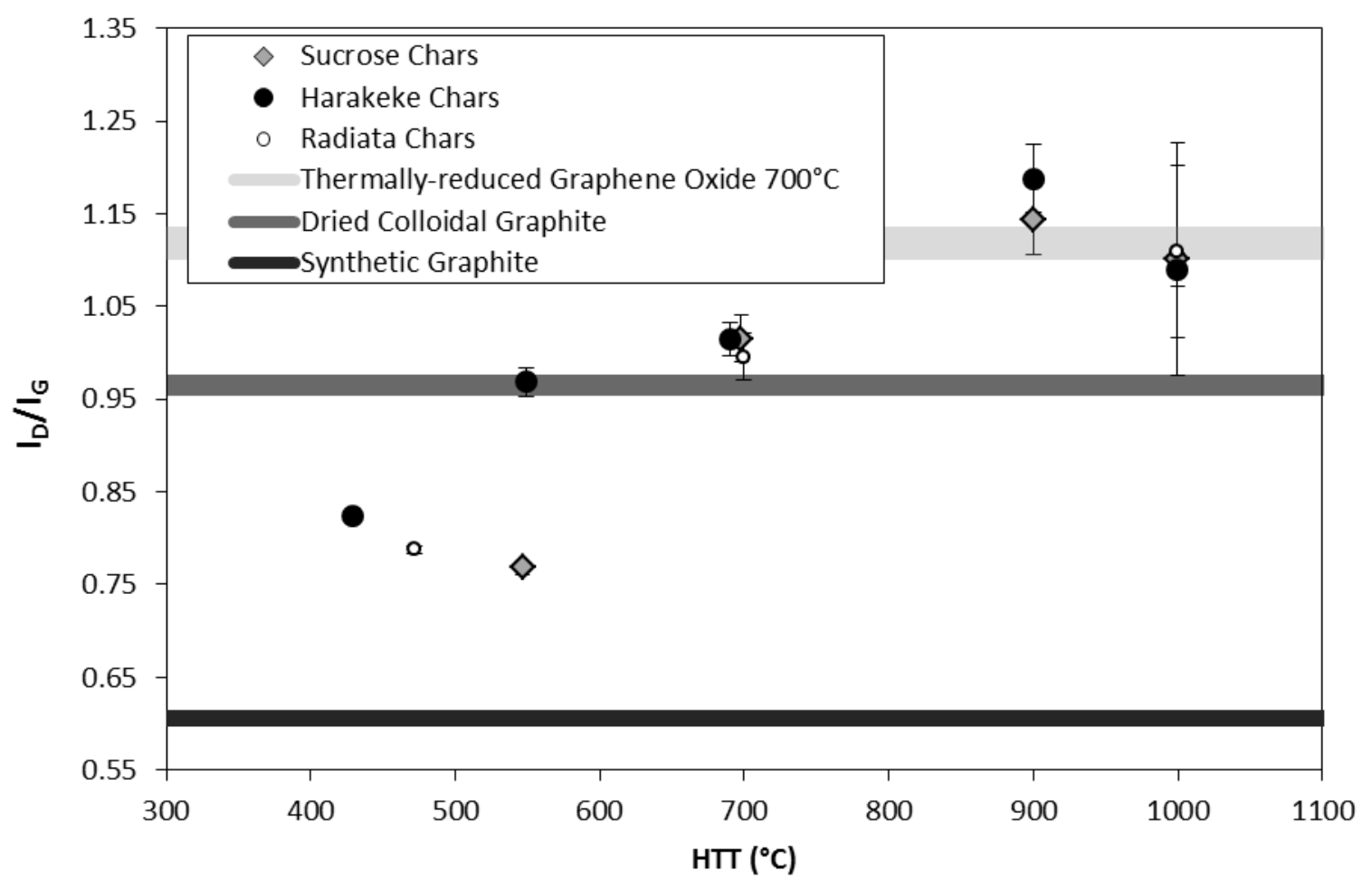

Fig. 10: Plot of $I_{D} / I_{G}$ height intensity ratios as a function of heat treatment temperature for chars.

Horizontal guide lines represent approximate $I_{D} / I_{G}$ height intensity ratios measured for various graphites, and the thermally-reduced graphene oxide sample prepared at an $\mathrm{HTT} \approx 700{ }^{\circ} \mathrm{C}$. 
A common application of $I_{D} / I_{G}$ type ratios is in estimating the in-plane crystallite size $\left(L_{a}\right)$ in graphite and graphite-like materials. As higher $\mathrm{I}_{\mathrm{D}} / \mathrm{I}_{\mathrm{G}}$ ratios correlate with a greater proportion of hexagonal rings in close proximity to the edge or domain boundary of a graphene-like network, then a decrease in $\mathrm{I}_{\mathrm{D}} / \mathrm{I}_{\mathrm{G}}$ ratios correlates with larger, less defective graphite/graphene sheets, and the process of graphitisation $[10,17,31,70]$. These $I_{D} / I_{G}$ type ratios are often based on the Tuinstra-Koenig correlation with some more recent adjustments. Peak height ratios or peak area ratios are used by different researchers; and Zickler et. al. have already commented on how some literature is not clear about whether areas or heights were used [10]. It is important to note that these Tuinstra-Koenig type correlations do not work when coherent domains are smaller than about 2-4 nm across, and $\mathrm{I}_{\mathrm{D}} / \mathrm{I}_{\mathrm{G}}$ type ratios typically reach a maximum when $\mathrm{L}_{\mathrm{a}} \approx 2-10 \mathrm{~nm}[10,31,71,72]$, which reflects how in these small graphene-like domains potentially all hexagonal rings are close enough to edges/defects to be "activated" and produce D band signals [32]. 
The increase in $I_{D} / I_{G}$ height ratios with increasing HTT, such as observed for both the carbonisation of chars (Fig. 10) and the thermal reduction of graphene oxide (Table S2, see Supplementary material), indicates that both materials contain graphene-like structures which are growing by consuming and re-organising more amorphous structures as they are exposed to increasingly severe thermal treatments. This can be interpreted as also representing the ordering of aromatic clusters towards graphene-like networks with coherent domain sizes or average distance between defects [58] (or between significant curvature of the sheets [61]) approaching a few nanometres across. Increasing $\mathrm{I}_{\mathrm{D}} / \mathrm{I}_{\mathrm{G}}$ type ratios have been previously reported for graphene oxide during the reduction process $[63,71,73,74]$, although many researchers in the graphene oxide field appear to have so-far overlooked the recent literature which clearly demonstrates that maxima of $I_{D} / I_{G}$ type ratios typically correspond to graphene-like coherent domains having diameters and/or interdefect distances of $\approx 2-4 \mathrm{~nm}$ $[10,31,71,72]$. The $\left(I_{D}-I_{V}\right) /\left(I_{G}-I_{V}\right)$ height ratios (Table $S 2$, see Supplementary material) could be useful as they do not require additional baseline corrections for their measurement. However, these values show similar overall trends to the $\mathrm{I}_{\mathrm{D}} / \mathrm{I}_{\mathrm{G}}$ height ratios and do not require further discussion. 


\subsubsection{A band and valley-based parameters}

The A band and valley-based parameters measured in this data processing procedure involve signals which appear between the typical graphene-like $\mathrm{G}$ band and D band and are intended to provide some information about amorphous carbon content. Across the literature, Raman signals which occur between the G and D bands are often assigned as the D" (or D3) band $[10,17,28,33,75]$ or A band [13], or measured with another parameter such as valley height $\left(\mathrm{I}_{\mathrm{V}}\right)$ [29]. In many cases, these signals are interpreted as being due to $\mathrm{sp}^{2}$ amorphous and/or "graphitic amorphous" material without any more detailed description or discussion. Wu et. al. when using Raman (1064 nm excitation laser) in an investigation of chars produced from Mallee tree (Eucalyptus loxophleba lissophloia) biomass (wood, bark, and leaves), compiled a far more detailed assignment of these amorphous carbon bands, including: $1540 \mathrm{~cm}^{-1}$ (labelled $\mathrm{G}_{\mathrm{r}}$ ) as small clusters of 3-5 fused aromatic rings $\left(\mathrm{sp}^{2}\right), 1465 \mathrm{~cm}^{-1}$ (labelled $\mathrm{V}_{\mathrm{l}}$ ) as aromatic rings with attached methyl or methylene groups $\left(\mathrm{sp}^{2}\right.$ and $\mathrm{sp}^{3}$ bonded carbon), and $1380 \mathrm{~cm}^{-1}$ (labelled $\mathrm{V}_{\mathrm{r}}$ ) as aromatic rings with attached methyl groups $\left(\mathrm{sp}^{2}\right.$ and $\mathrm{sp}^{3}$ ) [59]. Kim et. al. employed Raman analysis to investigate chars produced from switchgrass and pine wood; they used similar chemical/structural assignments to Wu et. al. (although different peak names), and these types of molecular assignments appear to originate from earlier coal research $[60,76]$ These types of molecular assignments are debatable, as it is not clear if sufficient evidence exists to make such detailed assignments. 
Only char samples prepared at lower HTTs $\left(\right.$ below $\approx 550{ }^{\circ} \mathrm{C}$ ) and the graphene oxide samples with minimal laser exposure had distinct and broad A band signals which could be assigned using the data processing procedures in this current work (Table S3, see Supplementary material). The modified data processing procedure with the photoluminescence background slope subtracted was required to measure the A band based parameters in many of these samples. The values for mean A band positions tended to remain around $1420-1430 \mathrm{~cm}^{-1}$ across all the sample types were it was able be measured. By extrapolating from amorphous carbon dispersive trends studied by Ferrari and Robertson [22], it can be estimated that the signal at $\approx 1420-1430 \mathrm{~cm}^{-1}$ represents a type of amorphous carbon that could contain: $\approx 40 \%$ $\mathrm{sp}^{2}$ bonded carbon, $\approx 60 \% \mathrm{sp}^{3}$ bonded carbon, and a reasonably large hydrogen content. This is an extremely rough estimate based on trends observed for synthetic "diamond-like" and hydrogenated amorphous carbon materials $[22,55]$, which are probably different to the amorphous carbon in biomass chars (and graphene oxides) in respect to oxygen content and overall chemical structure. After adjusting for the different lasers used (again based on dispersive trends [22]) it can be estimated that the $1430 \mathrm{~cm}^{-1}$ signal on this instrument is probably the same signal that appears near $1380 \mathrm{~cm}^{-1}$ if analysed on the instrument used by Wu et. al. [59], who interpreted this signal to be aromatic rings with methyl groups and/or amorphous carbon structures [59], Their interpretation is close (in an extremely broad chemical sense) to the rough estimate of the type of amorphous carbon described earlier, and both are generally consistent with some of the broad descriptions and NMR evidence of the amorphous carbon in lower HTT chars containing both aromatic and aliphatic structures [7, 77, 78]. Therefore, the A band measured with this methodology likely represents a $\mathrm{G}$ band arising from very small domains of $\mathrm{sp}^{2}$ bonded carbon $\left(<1-2\right.$ benzene rings worth of $\mathrm{sp}^{2}$ carbon and this $\mathrm{sp}^{2}$ carbon not necessarily being in hexagonal ring structures) surrounded and 
localised by a significant proportion of $\mathrm{sp}^{3}$ bonding in a very amorphous material. In both the chars and graphene oxide this A band is reduced in relative intensity and then disappears with increasing HTTs (and with increasing laser exposure in the case of graphene oxide).

Sharp and intense signals were detected the spectra obtained from regular fullerenes $\left(\mathrm{C}_{60}\right.$ and $\mathrm{C}_{70}$ ) within the $1400 \mathrm{~cm}^{-1}$ to $1470 \mathrm{~cm}^{-1}$ region where the A band was measured in this current work. Questions concerning if (or how) such signals are related to the signals generated by amorphous carbons in the context of structural features will require further investigation.

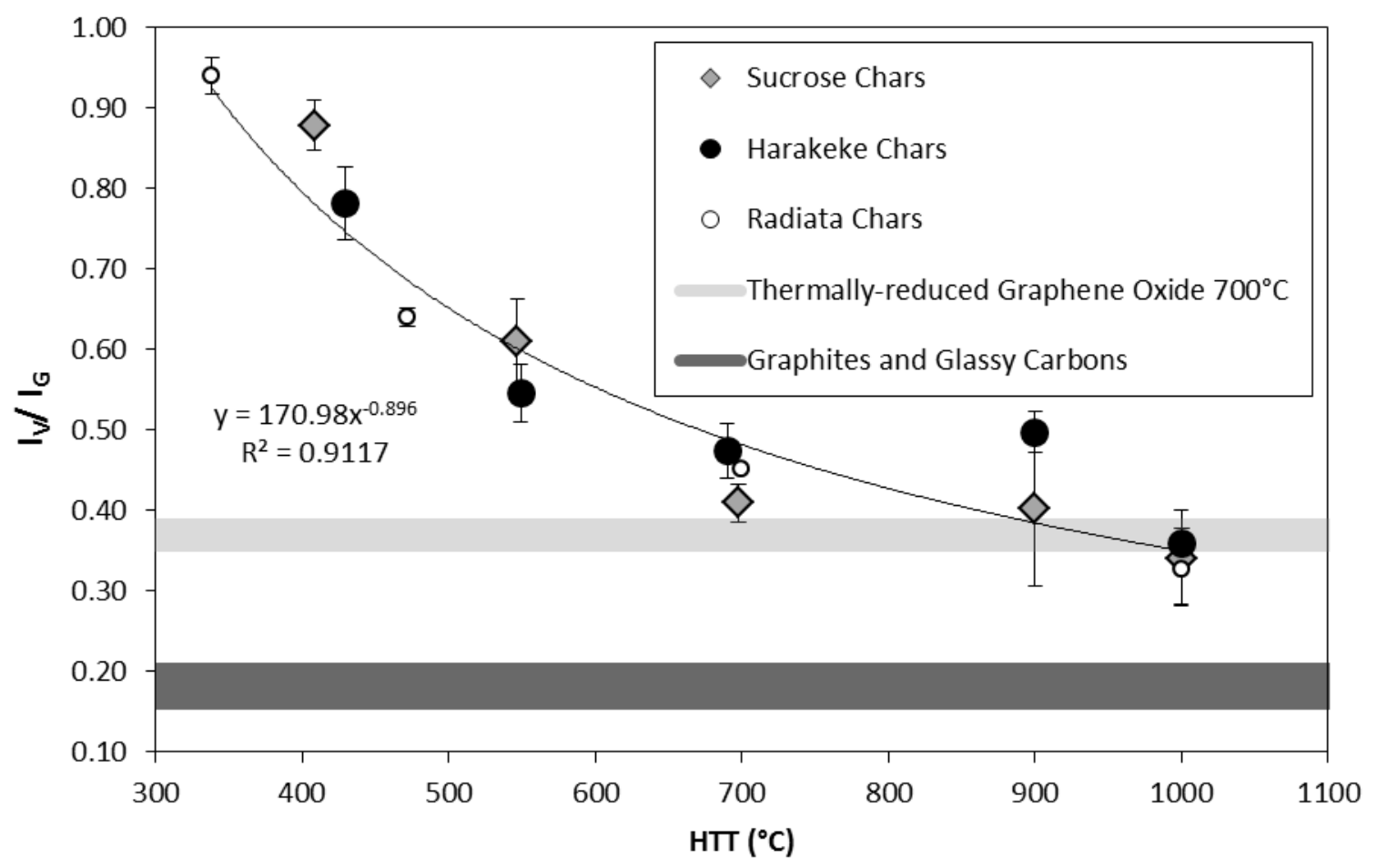

Fig. 11: Plot of $I_{V} / I_{G}$ height intensity ratios as a function of heat treatment temperature for chars. All values measured using photoluminescence-based modified data processing procedure. Horizontal guide lines represent approximate $I_{V} / I_{G}$ height intensity ratios measured for glassy carbon, graphite, and the thermally-reduced graphene oxide sample prepared at HTT $\approx 700{ }^{\circ} \mathrm{C}$. Trend line uses mean values and includes chars from all three precursors. 
The trend of decreasing $\mathrm{I}_{\mathrm{V}} / \mathrm{I}_{\mathrm{G}}$ height ratios with increasing HTT was found for the chars produced from all three precursors (Fig. 11 and Table S4, see Supplementary materials). Similar decreases in this valley-based parameter have been interpreted as the "elimination of amorphous materials" when it was originally used to monitor structural changes in coal chars and metallurgical cokes when they were exposed to increasingly severe heat treatments and air oxidation at $500{ }^{\circ} \mathrm{C}[29]$. Below HTTs of $\approx 700{ }^{\circ} \mathrm{C}$ the variation in $\mathrm{I}_{\mathrm{V}} / \mathrm{I}_{\mathrm{G}}$ height ratios appears to be more precursor dependent. In contrast, $\mathrm{I}_{\mathrm{V}} / \mathrm{I}_{\mathrm{G}}$ values for chars produced at HTTs approaching $1000{ }^{\circ} \mathrm{C}$ appear similar regardless of precursor; although the $99 \%$ confidence intervals tended to be larger, which may be due to low signal intensity in the valley increasing the influence of baseline noise. The large change in $I_{V} / I_{G}$ height ratios between HTTs of $\approx 400{ }^{\circ} \mathrm{C}$ and $\approx 700{ }^{\circ} \mathrm{C}$ is likely to correspond to the removal of amorphous carbon through pyrolysis and/or conversion of the amorphous material into more ordered graphenelike sheets over this HTT range. These results fit with the dynamic molecular structure diagram for biomass-derived black carbon presented by Keiluweit et. al.[7], which has graphene-like sheets (with turbostratic disorder) growing through and consuming the amorphous carbon phase until the amorphous carbon phase is close to eliminated at HTTs of $700{ }^{\circ} \mathrm{C}$ and above. The $\mathrm{I}_{\mathrm{V}} / \mathrm{I}_{\mathrm{G}}$ height ratios appear to level out at values approaching 0.4 at HTTs of between $\approx 700{ }^{\circ} \mathrm{C}$ and $\approx 1000{ }^{\circ} \mathrm{C}$ across chars derived from different precursors and have values similar to graphene oxides samples thermally reduced at $\approx 700-900{ }^{\circ} \mathrm{C}$. These $\approx$ 0.4-0.5 values obtained for $I_{V} / I_{G}$ height ratios likely represent the overlap of broad D and $G$ bands in the valley and may not represent any amorphous carbon content. If this is correct then the small decreases in mean $\mathrm{I}_{\mathrm{V}} / \mathrm{I}_{\mathrm{G}}$ height ratios as HTTs increase above $\approx 700{ }^{\circ} \mathrm{C}$ are more likely to be due to narrowing of $\mathrm{D}$ and $\mathrm{G}$ bands than reduction in amorphous carbon content. 
There was a large decrease in $I_{V} / I_{G}$ height ratios which appeared to have occurred during the early stages of the reduction of graphene oxide caused by a mild heat treatment $\left(\approx 400^{\circ} \mathrm{C}\right)$ or prolonged exposure to the Raman laser (Table S4, see Supplementary materials). This trend can be interpreted as the conversion of amorphous carbon into graphene-like carbon via the removal of $\mathrm{sp}^{3}$ bonded functional groups which is consistent with what is known to occur during the thermal reduction of graphene oxide $[63,73]$. The $I_{V} / I_{G}$ results demonstrate some broad similarities between the reduction of graphene oxides and carbonisation of chars, which likely reflect the well-known vulnerability of amorphous $\mathrm{sp}^{3}$ bonded material to conversion into more stable $\mathrm{sp}^{2}$ forms during thermal treatments $[14,38]$. The significant decrease in $I_{V} / I_{G}$ height ratios due to even mild Raman laser exposure is consistent with the extreme (photo)thermal instability of most of the $\mathrm{sp}^{3}$ bonded functional groups in graphene oxide materials [63], and their tendency to be removed with exposure to intense light [19, 71]. 


\subsubsection{Photoluminescence slope-based parameter}

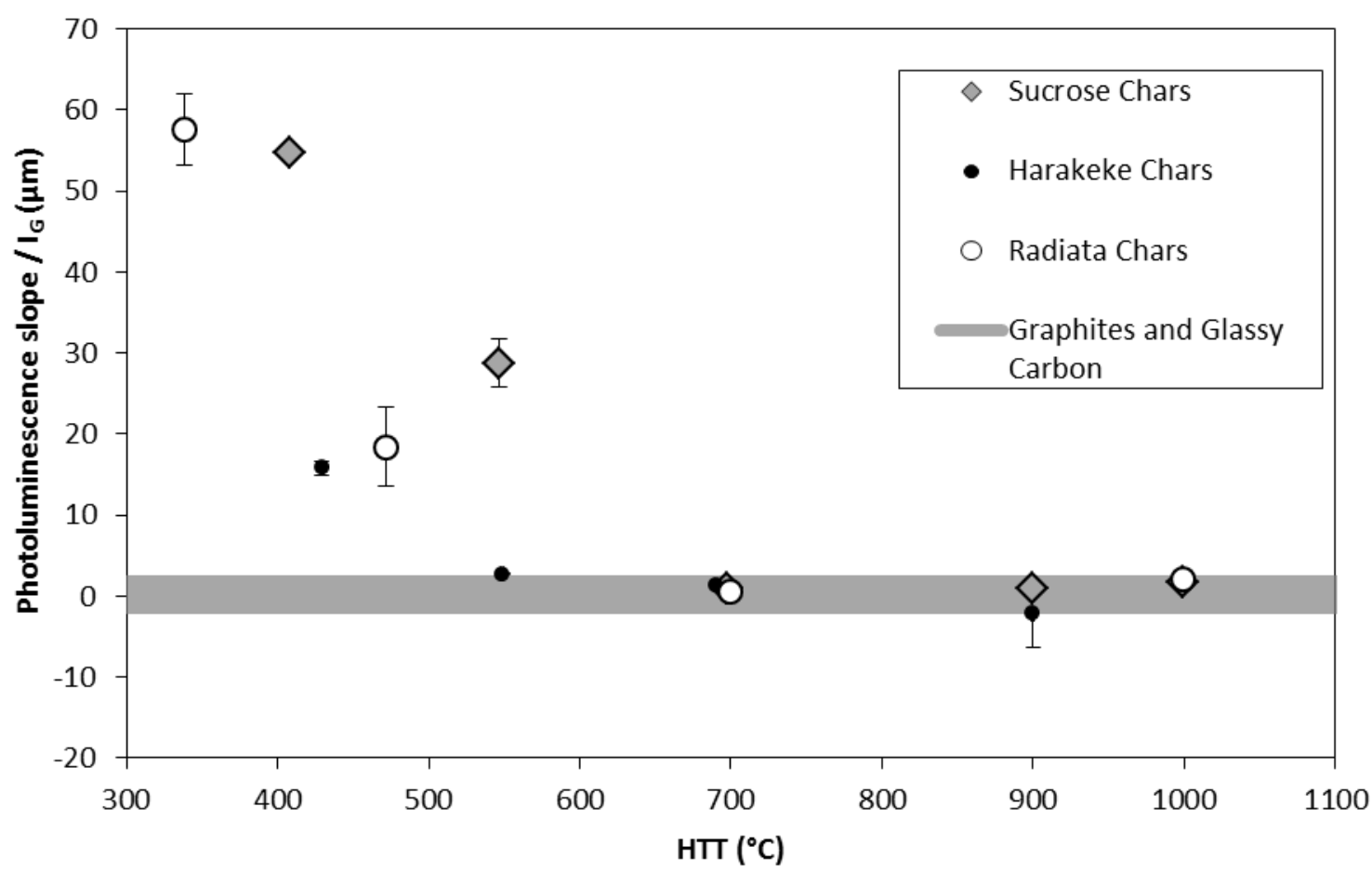

Fig. 12: Photoluminescence $s$ slope $/ \mathrm{I}_{\mathrm{G}}$ as a function of heat treatment temperature for chars.

Horizontal guide line represents approximate Photoluminescence slope / $I_{G}$ measured for glassy carbon and graphite. 
The Raman spectra of low HTT chars demonstrated what appears to be a photoluminescence background slope and had slope-based parameter values which were found to decrease as HTTs were increased (Fig. 12). Similar photoluminescence background slopes divided by $\mathrm{I}_{\mathrm{G}}$ values have been previously correlated to the hydrogen content in amorphous carbon films. Increases in the hydrogen content (above 20 atom \%) within amorphous carbon samples has been reported to exponentially increase parameter values which are based on the slope of the photoluminescence background, when using visible light wavelength excitation [22, 24, 34, 79]. This suggests that the slope of the photoluminescence background might also be an indicator of decreasing hydrogen content in chars. However, there is a lack of existing literature applying this photoluminescence background slope to biomass chars. The photoluminescence slope / $\mathrm{I}_{\mathrm{G}}$ values level out and approach zero and in the cases of: chars carbonised above $\approx 700{ }^{\circ} \mathrm{C}$, thermally-reduced graphene oxide and the commercial samples of graphite, glassy carbon and carbon fibres (Table S5, see Supplementary material). This indicates minimal levels of hydrogen content, although there are some potential issues with this interpretation. In these cases, noise and minor Raman signals may greatly influence the values as indicated by the relatively large $99 \%$ confidence intervals and the negative values. How the hydrogen is bonded or what type of carbon structure it is bonded to might also make a difference to these values, although this is unclear without further experiments using both the $785 \mathrm{~nm}$ laser and more standard compounds/materials with well-defined structures and compositions. Initially, based on existing literature on hydrogenated amorphous carbon films $[24,34]$ it can be expected that the photoluminescence slope will occur in the Raman spectra when hydrogen content exceeds $\approx 20$ atom $\%$, and the hydrogen is in $\mathrm{C}$ - $\mathrm{H}$ bonded functional groups attached to amorphous carbon with a mix of small $\mathrm{sp}^{2}$ clusters localised by a predominantly $\mathrm{sp}^{3}$ bonded carbon matrix. It has been previously reported that hydrogen 
contents in wood chars decrease with increasing HTT (or final charring temperatures) and the $\mathrm{H} / \mathrm{C}$ atomic ratio drops below $\approx 0.2$ at $\approx 700{ }^{\circ} \mathrm{C}[1,7]$, which is broadly consistent with the photoluminescence slope-based results obtained so far, suggesting that this type of parameter could be further applied and developed for routine semi-quantitative estimates of hydrogen content in the more amorphous, lower HTT chars where H/C atom ratios are expected to exceed $\approx 0.2$.

The spectra of the graphene oxide samples also exhibited what appeared to be a photoluminescence slope. The photoluminescence slope / $\mathrm{I}_{\mathrm{G}}$ values measured for graphene oxide samples in Fig. 13, show a significant decrease as the graphene oxide was reduced using the laser on the Raman instrument. Given that the existing literature applies such photoluminescence slope-based parameters to hydrogenated amorphous carbon films it was expected that this parameter would only be suitable for detecting hydrogen content in $\mathrm{C}-\mathrm{H}$ groups [24, 34], and not suitable for graphene oxide (which is regarded as containing hydrogen as predominantly C-OH functional groups [63]). The large photoluminescence slope-based values measured for the graphene oxide sample were unexpected and suggests that this parameter may also be measuring other types of functional groups (such as hydrogen content in $\mathrm{C}-\mathrm{OH}$ functional groups as well as $\mathrm{C}-\mathrm{H}$ bonded hydrogen) or could be measuring another feature of amorphous carbon structures which tends to generally correlate with hydrogen (and/or oxygen) content. 


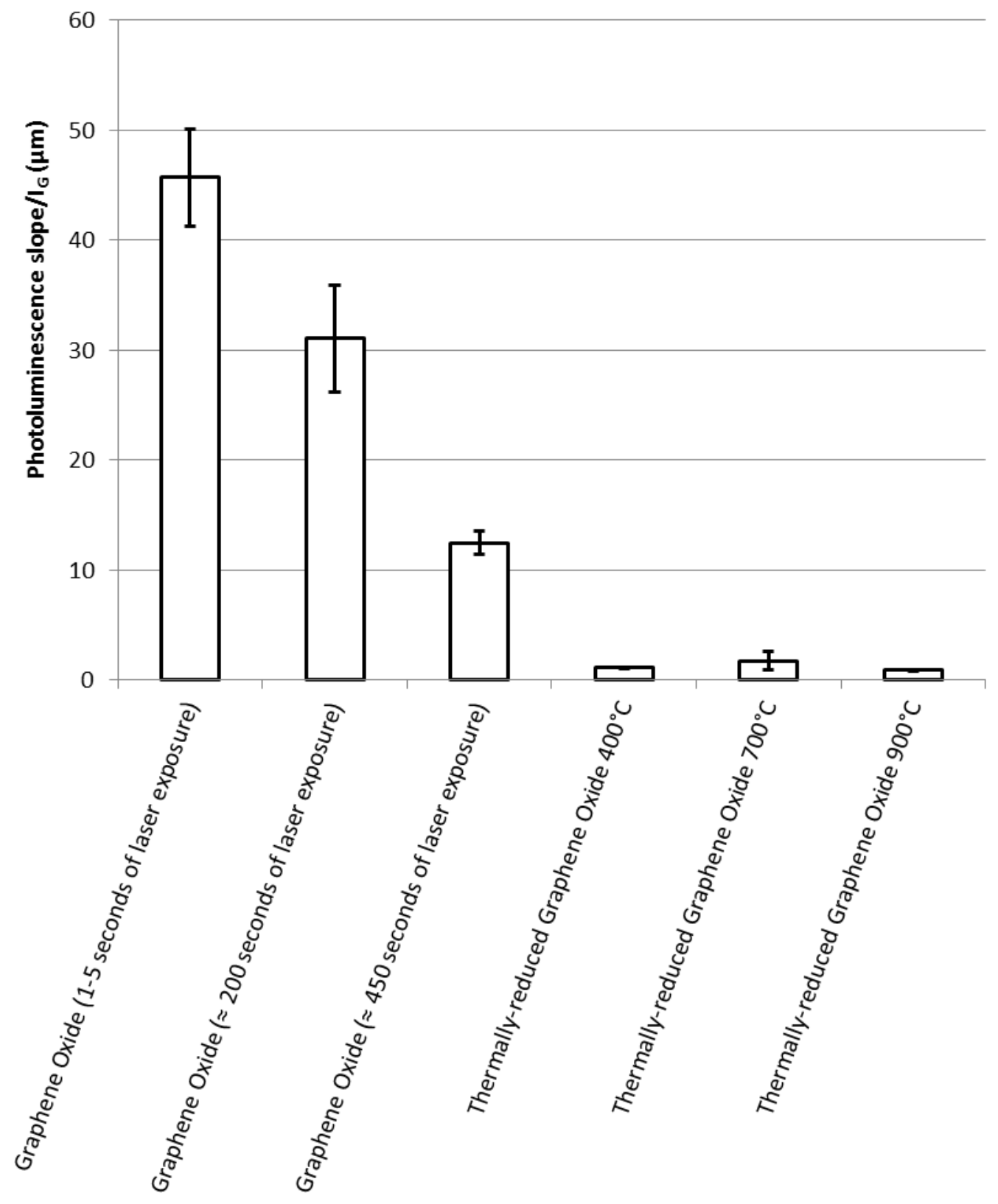

Fig. 13: Photoluminescence slope/ $I_{G}$ as graphene oxide is reduced using increasingly severe treatments 


\subsubsection{Other Raman bands}
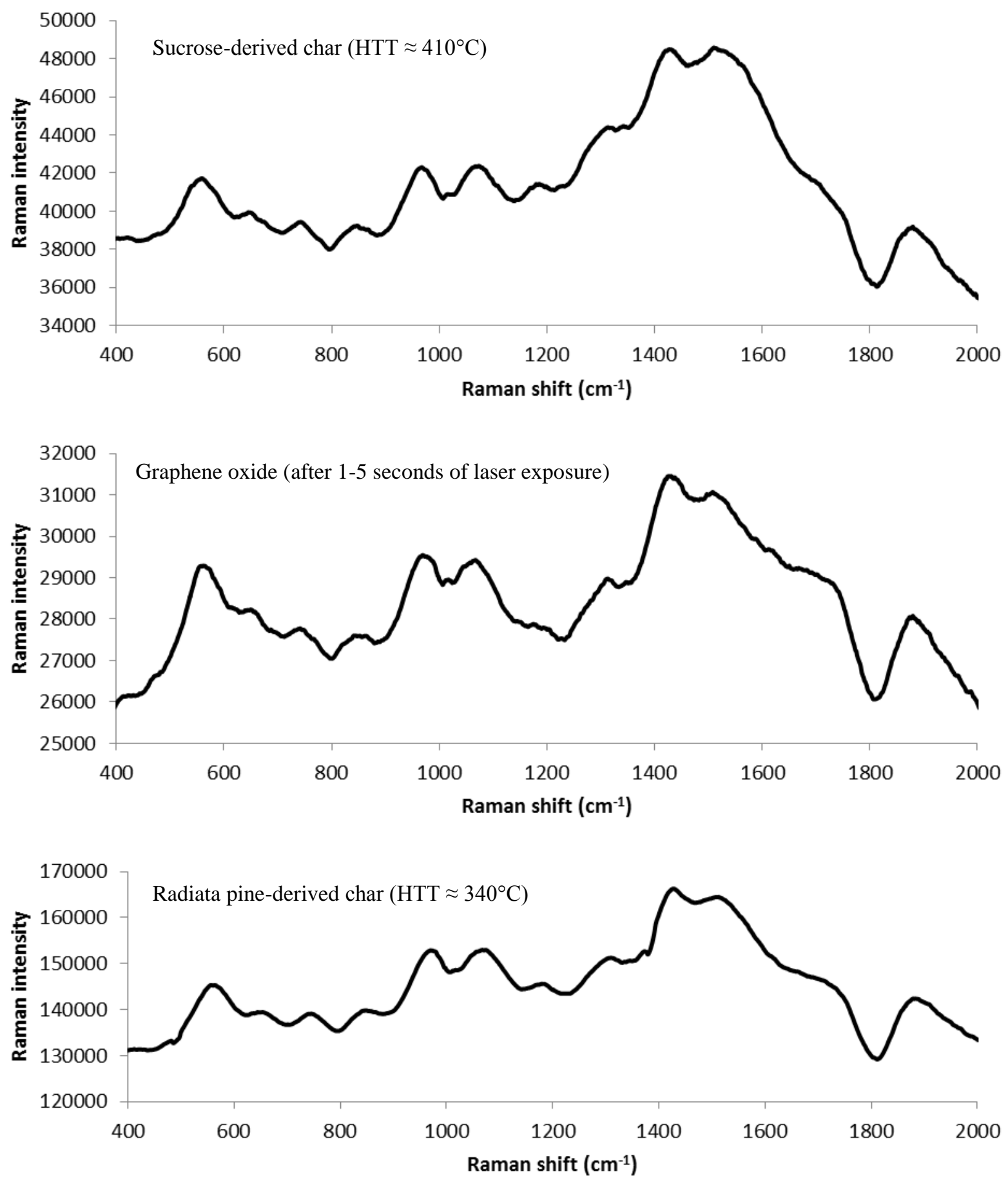

Fig. 14: Raman spectra which are examples of the most amorphous and oxygen-rich materials analysed in this current work. Lowest HTT radiata pine-derived and sucrose-derived chars compared with a graphene oxide sample analysed with the shortest laser exposure. Spectra were processed with $15 \mathrm{~cm}^{-1}$ smoothing of raw data using a moving mean followed by subtraction of the photoluminescence slope. 
As demonstrated in Fig. 14, the spectra of the most amorphous samples (both lowest HTT chars and the least-reduced graphene-oxide sample) all featured a greater number of prominent and broad bands across the wider spectrum. As the signal measured as the A band was the most intense of these it has been measured routinely in this current data processing procedure and attempts have been made to interpret the A band in the context of different forms of amorphous carbon. In a similar trend to the A band, many of the other common signals (more intense signals located near $\approx 570 \mathrm{~cm}^{-1}, \approx 970 \mathrm{~cm}^{-1}, \approx 1070 \mathrm{~cm}^{-1}, \approx 1890 \mathrm{~cm}^{-1}$ ) seen in Fig. 14 generally appeared to be rapidly reduced in intensity relative to traditional $1^{\text {st }}$ order carbonaceous bands (D and G) as HTTs were increased. Given that both graphene oxide [19] and the lower HTT chars [1, 12] are expected to be rich in oxygen content, it is logical to attribute some of these signals to presence of oxygen-related functional groups, especially in cases where similar signals are not found in the spectra reported for (oxygenpoor or oxygen-free) thin film amorphous carbons [22, 24, 31, 38, 55]. Although these minor signals were not a focus of the current investigation, their occurrence is interesting and should be studied further with the goal of assigning these signals to specific chemical features. 
When prepared using HTTs of $\approx 700{ }^{\circ} \mathrm{C}$ and above, both carbonised chars and thermallyreduced graphene oxides featured a Raman band near $1180 \mathrm{~cm}^{-1}$ which was observed as a prominent shoulder on the lower wavenumber side of the D band (Fig. 2, Fig. 4, Fig. S1 and Fig. S2). Interestingly, the spectra obtained from dried colloidal graphite did not feature this prominent shoulder despite the presence of abundant D band intensity (Fig. 5). This indicates that this signal near $1180 \mathrm{~cm}^{-1}$ is related to a kind of structural feature (and/or a specific type of disorder) which is common within samples of carbonised chars and thermally-reduced graphene oxides, but negligible within the colloidal graphite sample. This shoulder could be tentatively interpreted as relating to structural features where pentagonal rings and/or other non-hexagonal rings exist within graphene-like networks. This interpretation might be supported by high resolution electron microscope images which have clearly demonstrated that these structures occur in similar materials (activated carbons and other reduced graphene oxides) $[64,65]$. The occurrence of Raman signals in the general vicinity $\left( \pm 50 \mathrm{~cm}^{-1}\right)$ of $\approx 1180 \mathrm{~cm}^{-1}$ in the spectra of regular fullerenes (Fig. 6), carbon nano-onions [54], and in the surface-enhanced Raman scattering spectra of SWCNTs (which have been reported as evidence of Stone-Thrower-Wales defects) [80] may also support this interpretation. However, a great many suggested assignments and tentative interpretations have already been applied to this shoulder when it occurs in the Raman spectra of carbonised chars $[9,33,59$, $75,76,81]$ and other carbonaceous materials $[28,82]$. It would take a small review article to comprehensively describe and discuss this diverse range of potential interpretations. Thus, great caution is needed when assigning this shoulder near $\approx 1180 \mathrm{~cm}^{-1}$ as multiple structural/chemical features may generate signals in this part of the spectrum. The assumptions that underpin many interpretations of Raman signals near $1180 \mathrm{~cm}^{-1}$ may subsequently be found to be wrong, especially with newer research on the Raman bands 
associated with "diamond-like" $\mathrm{sp}^{3}$ bonded materials now contradicting some earlier assignments common in these fields $[22,83]$.

Second-order Raman bands [17, 32, 33] which typically occur at wavenumbers above 2000 $\mathrm{cm}^{-1}$ were not routinely measured in this current work. This was due to poor signal intensities, additional noise, and extremely distorted baselines which generally occurred at this end of the spectrum when carbonaceous materials were analysed using this particular methodology. A notable exception was in the samples of single-walled carbon nanotubes with a prominent band at $(2569.4 \pm 0.6) \mathrm{cm}^{-1}$, which shifted to $(2620 \pm 3)$ after the air oxidation treatment and these are likely to be $\mathrm{G}^{\prime}$ bands $[32,39]$. During the trial experiment to monitor laser heating induced $\mathrm{G}$ band redshift, it was observed that increasing the laser power setting (from $20 \%$ to $100 \%$ of maximum) employed to analyse the sample of dried colloidal graphite caused a great increase in the relative intensity of the $\mathrm{G}^{\prime}$ band relative to the $\mathrm{G}$ band. At these high laser power settings, more of the expected second-order bands in this graphite sample became prominent, such as a lower wavenumber shoulder on the $\mathrm{G}^{\prime}$ band which could be the splitting of this signal which Lespade et. al. found to be associated with tri-periodic order [27] and is generally attributed to graphitic ABA stacking [31, 32]. This suggested that higher laser powers could be used on this instrument for future in-depth investigation of these secondorder Raman bands. However, relative intensity changes caused by laser power settings may pose problems to the use of intensity ratios involving these second order bands, such as those proposed by Larouche and Stansfield [61]. 


\subsubsection{Assessing the carbonisation of chars using Raman spectroscopy}

It has been discussed by various groups of researchers that positions of the D band and $G$ band or $\mathrm{I}_{\mathrm{D}} / \mathrm{I}_{\mathrm{G}}$ type ratios are not appropriate parameters for assessing the degree of disorder/order and monitoring the graphitisation pathway. Such researchers prefer the use of parameters based on $\mathrm{G}$ band width measurements to assess the degree of graphitisation and the related reduction in structural disorder $[33,84]$. $\mathrm{G}$ band width measurements were not made in this current work as the G band usually overlapped considerably with the D band or other signals and deconvolution-type, curve-fitting was avoided with the goal of simplicity and consistency. The researchers which consider $\mathrm{G}$ band width to be the most suitable and reliable parameter are often focused on the geological development of graphites or the high temperature $\left(>2000{ }^{\circ} \mathrm{C}\right.$ ) industrial graphitisation process. Judging by their results and conclusions [33, 84], G band width is likely to be an ideal choice of parameter for monitoring the process of graphitisation. However, this current work and the conclusions surrounding which parameters are most relevant and reliable are focused on the process of carbonisation which mostly takes place below $1000{ }^{\circ} \mathrm{C}$. Further evidence that $\mathrm{G}$ band width measurements are more appropriate parameters for monitoring structural development above $1000{ }^{\circ} \mathrm{C}$, than below $1000{ }^{\circ} \mathrm{C}$ can be seen in a Raman investigation involving the pyrolysis of spruce wood by Zickler et. al. [10]. 
Apparent $\mathrm{G}$ band position has so far proven to be the most reliable parameter for rapidly assessing the extent of carbonisation (and estimating the effective HTT reached by that sample) in chars from the three precursors analysed. The $\mathrm{G}$ band position parameter is useful because the band clearly appears in the spectra over a wider range of HTTs than the other parameters measured. The measured positions of the $\mathrm{G}$ band also increase in what appears to be a precursor independent, linear trend (Fig. 7) between HTTs of $\approx 400{ }^{\circ} \mathrm{C}$ to $\approx 700{ }^{\circ} \mathrm{C}$. This HTT range is important because significant developments in interesting and useful properties (such as hardness, modulus, electrical conductivity, and porosity) typically occur over this stage of the carbonisation process $[2,8,18,85]$. The apparent precursor independent nature of the $\mathrm{G}$ band position during the carbonisation of chars is consistent with these condensed aromatic networks (and graphene-like structures) being new features not present in the original precursor and instead being a product of HTT driven aromatic growth/condensation. Although the $\mathrm{G}$ band position appears so far to be the most applicable parameter for rapidly estimating the effective HTT used to produce a given char, it is important to also consider other parameters such as $\mathrm{I}_{\mathrm{V}} / \mathrm{I}_{\mathrm{G}}$ ratios, $\mathrm{I}_{\mathrm{D}} / \mathrm{I}_{\mathrm{G}}$ ratios and $\mathrm{D}$ band positions which also significantly change during the carbonisation process and with some limitations can also be used to estimate effective HTTs and potentially assess specific aspects of the nanostructural development which has occurred during the heat treatment. $\mathrm{I}_{\mathrm{V}} / \mathrm{I}_{\mathrm{G}}$ ratios and the photoluminescence slope-based parameter are more sensitive to changes at lower HTTs and may provide more information about the amorphous carbon content. In contrast, $\mathrm{I}_{\mathrm{D}} / \mathrm{I}_{\mathrm{G}}$ ratios and $\mathrm{D}$ band position relate to the nanometre-sized, graphene-like components and therefore are more suitable parameters for assessing and studying the carbonised chars produced at higher HTTs. 
The lower HTT sucrose-derived chars had many parameter values (such as $\mathrm{I}_{\mathrm{D}} / \mathrm{I}_{\mathrm{G}}$ ratios, $\mathrm{D}$ band positions, and the photoluminescence slope / $\mathrm{I}_{\mathrm{G}}$ ratios) which were significantly different to chars produced from the two lignocellulosic precursors. This may be due to some kind of precursor dependency in lower HTT chars and/or the fact that the highly crystalline sucrose progresses through a liquid caramel phase before it chars which may cause it to initially lag behind the other types of char. The parameter values measured for the carbonised chars produced from all three precursors converged as the HTT used to carbonise these chars was increased towards $\approx 1000{ }^{\circ} \mathrm{C}$. This evidence indicating a somewhat precursorindependent, carbonaceous nanostructure developing as HTTs approach $1000{ }^{\circ} \mathrm{C}$ is consistent with previously published X-ray diffraction and scattering studies which reached similar conclusions after analysing carbonised chars (HTTs near $1000{ }^{\circ} \mathrm{C}$ ) produced from a range of carbohydrate and lignocellulosic precursors $[4,66]$. 
This Raman methodology which employs near-infrared excitation and the measurement of traditional $1^{\text {st }}$ order bands is primarily observing $\mathrm{sp}^{2}$ bonded carbon within structural features on scales of a few nanometres. What these results demonstrate is that the type of disorder present in lower HTT chars is similar to that found in amorphous carbons and the type of disorder present in higher HTT carbonised chars is more similar to that which is found in thermally-reduced graphene oxides. Spectral features in chars produced at intermediate HTTs $\left(\approx 550^{\circ} \mathrm{C}\right)$ indicate the presence of both broad types of disorder. This observation and the ability to measure a number of spectral parameters which change significantly and reliably, allows Raman methodologies such as this to assess the extent of nanostructural development which occurs over the HTT range between $\approx 400^{\circ} \mathrm{C}$ and $\approx 900^{\circ} \mathrm{C}$. By observing this nanostructural development it is possible to estimate what effective HTT was applied during the carbonisation process. However, other factors may influence the carbonisation process and potentially change the way the nanostructure develops, thus correlations (such as the one demonstrated in Fig. 7) might change significantly as a result of major alterations to the carbonisation process. Such alterations could potentially include: the length of dwell/soak times at maximum temperature, the heating rate, changing to precursors with different chemistry (such as oxygen-poor hydrocarbons), and the addition of various catalysts. 


\section{Conclusions}

It was observed that even mild laser exposures during the acquisition of Raman spectra were able to begin the reduction process in a sample of graphene oxide. The spectra acquired from graphene oxide using the shortest laser exposure times (presumably the most un-reduced sample) possessed similar spectral features to those observed in very low HTT chars. These common features included a $\mathrm{G}$ band redshifted to $\approx 1510 \mathrm{~cm}^{-1}$, a distinct signal measured at a position of $\approx 1430 \mathrm{~cm}^{-1}$, and what appeared to be prominent photoluminescence slopes. These features are consistent with both this graphene oxide sample and these $\left(\mathrm{HTT}<400{ }^{\circ} \mathrm{C}\right)$ chars being forms of amorphous carbon.

An apparent increase (blueshift) in the measured $\mathrm{G}$ band positions was found to correlate well with the HTT used to produce chars over the HTT range of $\approx 400{ }^{\circ} \mathrm{C}$ to $\approx 700{ }^{\circ} \mathrm{C}$. This correlation can be used to assess the process of carbonisation, and thus far appears to be independent of the precursor used to produce the chars. The $\mathrm{G}$ band (as measured by this procedure) blueshifted from a position close to those measured for graphites toward values measured for a sample of commercial glassy carbon as the HTTs used to carbonise the chars is increased from $\approx 500{ }^{\circ} \mathrm{C}$ to $\approx 1000{ }^{\circ} \mathrm{C}$. 
$\mathrm{I}_{\mathrm{V}} / \mathrm{I}_{\mathrm{G}}$ height ratios were found to decrease significantly over the HTT range of $\approx 400{ }^{\circ} \mathrm{C}$ to $700{ }^{\circ} \mathrm{C}$ in chars, indicating the decrease in amorphous carbon content relative to the amount of $\left(\mathrm{sp}^{2}\right)$ carbon in hexagonal ring clusters and graphene-like networks. $\mathrm{I}_{\mathrm{D}} / \mathrm{I}_{\mathrm{G}}$ height ratios for chars were found to increase significantly over the HTT range of $500{ }^{\circ} \mathrm{C}$ to $900{ }^{\circ} \mathrm{C}$, indicating the growth and organisation of aromatic clusters towards graphene-like domains with inplane diameters a few nanometres across. During the reduction of the graphene oxide samples a general increase in $\mathrm{I}_{\mathrm{D}} / \mathrm{I}_{\mathrm{G}}$ height ratios and a decrease in $\mathrm{I}_{\mathrm{V}} / \mathrm{I}_{\mathrm{G}}$ height ratios was also observed indicating that a similar conversion of amorphous carbon to graphene-like domains was also occurring. The D band positions for chars were found to decrease (redshift) significantly over the HTT range of $500{ }^{\circ} \mathrm{C}$ to $1000{ }^{\circ} \mathrm{C}$, indicating that the near-edge structures of the aromatic clusters (and/or graphene-like domains) within carbonised chars become more similar to those which were present in the samples of glassy carbon, thermallyreduced graphene oxides, and graphites. 
Some clear differences were observed between the early stages of the reduction process in graphene oxides and the early stages of the carbonisation process in the chars produced from carbohydrate-based precursors. These differences are likely to relate to graphene oxide starting the process as a large covalent sheet-like network, and carbonisation being the process where such large covalent networks are developed from smaller aromatic structures. Despite these early differences, the Raman spectra (and parameter measurements) of carbonised chars and thermally-reduced graphene oxide appear to converge after both were prepared using heat treatments temperatures of $\approx 700{ }^{\circ} \mathrm{C}$. Comparison with Raman spectra obtained from graphites and regular fullerenes provided clear evidence to support the hypothesis that the nanostructure of carbonised chars is more "thermally-reduced graphene oxide-like", than "fullerene-like" or "graphite-like". The similarities and differences between carbonised chars and thermally-reduced graphene oxides will require further investigation using a wider range of techniques.

\section{Acknowledgements}

The Authors thank Steven Newcombe for crafting the quartz vessels required for this work, Georg Ripberger, Fatima Bashir, and colleagues at the New Zealand Biochar Research Centre (Massey University, NZ) for kindly supplying the radiata pine chars and production data, and the reviewers for their valuable suggestions. J. McDonald-Wharry was supported by the University of Waikato Doctoral Scholarship.

\section{Appendix A. Supplementary materials}

Supplementary material associated with this article can be found in the online version at..... 


\section{References}

[1] Antal MJ and Grønli M. The art, science, and technology of charcoal production. Ind Eng Chem Res 2003;42(8):1619-40.

[2] Jenkins GM and Kawamura K. Polymeric carbons - carbon fibre, glass and char. Cambridge: Cambridge University Press; 1976.

[3] Liu T, Luo RY, Qiao WM, Yoon SH, and Mochida I. Microstructure of carbon derived from mangrove charcoal and its application in $\mathrm{Li}$-ion batteries. Electrochim Acta 2010;55(5):1696-700.

[4] Smith AJ, MacDonald MJ, Ellis LD, Obrovac MN, and Dahn JR. A small angle X-ray scattering and electrochemical study of the decomposition of wood during pyrolysis. Carbon 2012;50(10):3717-23.

[5] Inagaki M, Konno H, and Tanaike O. Carbon materials for electrochemical capacitors. J Power Sources 2010;195(24):7880-903.

[6] Nunoura T, Dowaki K, Fushimi C, Allen S, Mészáros E, and Antal MJ. Performance of a first-generation, aqueous-alkaline biocarbon fuel cell. Ind Eng Chem Res 2007;46(3):734-44.

[7] Keiluweit M, Nico PS, Johnson MG, and Kleber M. Dynamic molecular structure of plant biomass-derived black carbon (biochar). Environ Sci Technol 2010;44(4):1247-53.

[8] Rhim YR, Zhang DJ, Fairbrother DH, Wepasnick KA, Livi KJ, Bodnar RJ, et al. Changes in electrical and microstructural properties of microcrystalline cellulose as function of carbonization temperature. Carbon 2010;48(4):1012-24. 
[9] Yamauchi S and Kurimoto Y. Raman spectroscopic study on pyrolyzed wood and bark of Japanese cedar: temperature dependence of Raman parameters. J Wood Sci 2003;49(3):235-40.

[10] Zickler GA, Smarsly B, Gierlinger N, Peterlik H, and Paris O. A reconsideration of the relationship between the crystallite size $\mathrm{L}_{\mathrm{a}}$ of carbons determined by X-ray diffraction and Raman spectroscopy. Carbon 2006;44(15):3239-46.

[11] Franklin RE. Crystallite growth in graphitizing and non-graphitizing carbons. Proc R Soc Lond 1951;209(1097):196-218.

[12] Rouzaud JN and Oberlin A. Structure, microtexture, and optical-properties of anthracene and saccharose-based carbons. Carbon 1989;27(4):517-29.

[13] Tzeng S-S and Pan J-H. Oxidative stabilization of petroleum pitch at high pressure and its effects on the microstructure and carbon yield after carbonization/graphitization. Mater Chem Phys 2002;74(2):214-21.

[14] Harris PJF. New perspectives on the structure of graphitic carbons. Crit Rev Solid State Mat Sci 2005;30(4):235-53.

[15] Buiel ER, George AE, and Dahn JR. Model of micropore closure in hard carbon prepared from sucrose. Carbon 1999;37(9):1399-407.

[16] Szczygielska A, Burian A, Dore JC, Honkimaki V, and Duber S. Local structure of saccharose- and anthracene-based carbons studied by wide-angle high-energy X-ray scattering. J Alloys Comp 2004;362(1-2):307-13.

[17] Bernard S, Beyssac O, Benzerara K, Findling N, Tzvetkov G, and Brown GE. XANES, Raman and XRD study of anthracene-based cokes and saccharose-based chars submitted to high-temperature pyrolysis. Carbon 2010;48(9):2506-16. 
[18] Zickler GA, Schoberl T, and Paris O. Mechanical properties of pyrolysed wood: a nanoindentation study. Philos Mag 2006;86(10):1373-86.

[19] Pei S and Cheng H-M. The reduction of graphene oxide. Carbon 2012;50(9):3210-28.

[20] Bagri A, Grantab R, Medhekar NV, and Shenoy VB. Stability and formation mechanisms of carbonyl- and hydroxyl-decorated holes in graphene oxide. J Phys Chem C 2010;114(28):12053-61.

[21] IUPAC. Compendium of chemical terminology: Gold book. Version 2.3.1: International Union of Pure and Applied Chemistry; 2012.

[22] Ferrari AC and Robertson J. Raman spectroscopy of amorphous, nanostructured, diamond-like carbon, and nanodiamond. Phil Trans R Soc Lond 2004;362(1824):2477-512.

[23] Osswald S, Havel M, and Gogotsi Y. Monitoring oxidation of multiwalled carbon nanotubes by Raman spectroscopy. J Raman Spectrosc 2007;38(6):728-36.

[24] Casiraghi C, Piazza F, Ferrari AC, Grambole D, and Robertson J. Bonding in hydrogenated diamond-like carbon by Raman spectroscopy. Diam Relat Mat 2005;14(3-7):1098-102.

[25] Kagi H, Tsuchida I, Wakatsuki M, Takahashi K, Kamimura N, Iuchi K, et al. Proper understanding of down-shifted Raman spectra of natural graphite: Direct estimation of laser-induced rise in sample temperature. Geochim Cosmochim Acta 1994;58(16):3527-30.

[26] Huang Y and Young RJ. Effect of fibre microstructure upon the modulus of PANand pitch-based carbon fibres. Carbon 1995;33(2):97-107. 
[27] Beyssac O, Goffé B, Petitet J-P, Froigneux E, Moreau M, and Rouzaud J-N. On the characterization of disordered and heterogeneous carbonaceous materials by Raman spectroscopy. Spectrochim Acta A: Mol Biomol Spectrosc 2003;59(10):2267-76.

[28] Sadezky A, Muckenhuber H, Grothe H, Niessner R, and Pöschl U. Raman microspectroscopy of soot and related carbonaceous materials: Spectral analysis and structural information. Carbon 2005;43(8):1731-42.

[29] Dong S, Alvarez P, Paterson N, Dugwell DR, and Kandiyoti R. Study on the effect of heat treatment and gasification on the carbon structure of coal chars and metallurgical cokes using fourier transform raman spectroscopy. Energy Fuels 2009;23(3):1651-61.

[30] Quirico E, Rouzaud J-N, Bonal L, and Montagnac G. Maturation grade of coals as revealed by Raman spectroscopy: Progress and problems. Spectrochim Acta A: Mol Biomol Spectrosc 2005;61(10):2368-77.

[31] Ferrari AC. Raman spectroscopy of graphene and graphite: Disorder, electronphonon coupling, doping and nonadiabatic effects. Solid State Commun $2007 ; 143(1-2): 47-57$.

[32] Jorio A, Dresselhaus G, and Dresselhaus MS. Raman spectroscopy in nanoscience and nanometrology: carbon nanotubes, nanographite and graphene. Hoboken NJ: Wiley-VCH; 2010.

[33] Cuesta A, Dhamelincourt P, Laureyns J, Martinezalonso A, and Tascon JMD. Raman microprobe studies on carbon materials. Carbon 1994;32(8):1523-32. 
[34] Buijnsters JG, Gago R, Jimenez I, Camero M, Agullo-Rueda F, and GomezAleixandre C. Hydrogen quantification in hydrogenated amorphous carbon films by infrared, Raman, and x-ray absorption near edge spectroscopies. J Appl Phys 2009;105(9):093510-7.

[35] Huang L, Liu Y, Ji L-C, Xie Y-Q, Wang T, and Shi W-Z. Pulsed laser assisted reduction of graphene oxide. Carbon 2011;49(7):2431-6.

[36] Sokolov DA, Shepperd KR, and Orlando TM. Formation of graphene features from direct laser-induced reduction of graphite oxide. J Phys Chem Lett 2010;1(18):2633-6.

[37] Weiler M, Sattel S, Giessen T, Jung K, Ehrhardt H, Veerasamy VS, et al. Preparation and properties of highly tetrahedral hydrogenated amorphous carbon. Phys Rev B 1996;53(3):1594-608.

[38] Robertson J. Diamond-like amorphous carbon. Mater Sci Eng R-Rep 2002;37(46):129-281.

[39] Heise HM, Kuckuk R, Srivastava A, and Asthana BP. Characterization of carbon nanotube filters and other carbonaceous materials by Raman spectroscopy-II: study on dispersion and disorder parameters. J Raman Spectrosc 2011;42(3):294302.

[40] Gupta S and Saxena A. Nanocarbon materials: probing the curvature and topology effects using phonon spectra. J Raman Spectrosc 2009;40(9):1127-37.

[41] Singhal R, Singh F, Tripathi A, and Avasthi DK. A comparative study of ioninduced damages in $\mathrm{C}_{60}$ and $\mathrm{C}_{70}$ fullerenes. Radiat Eff Def Solids 2009;164(1):3848. 
[42] Meilunas R, Chang RPH, Liu S, Jensen M, and Kappes MM. Infrared and Raman spectra of $\mathrm{C}_{60}$ and $\mathrm{C}_{70}$ solid films at room temperature. $\mathrm{J}$ Appl Phys 1991;70(9):5128-30.

[43] Paris O, Zollfrank C, and Zickler GA. Decomposition and carbonisation of wood biopolymers - a microstructural study of softwood pyrolysis. Carbon 2005;43(1):53-66.

[44] Colomban P, Gouadec G, Mathez J, Tschiember J, and Pérès P. Raman stress measurement in opaque industrial $\mathrm{Cf} / \mathrm{epoxy}$ composites submitted to tensile strain. Compos Pt A-Appl Sci Manuf 2006;37(4):646-51.

[45] Frank O, Tsoukleri G, Parthenios J, Papagelis K, Riaz I, Jalil R, et al. Compression behavior of single-layer graphenes. ACS Nano 2010;4(6):3131-8.

[46] Huang M, Yan H, Chen C, Song D, Heinz TF, and Hone J. Phonon softening and crystallographic orientation of strained graphene studied by Raman spectroscopy. Proc Natl Acad Sci USA 2009;106(18):7304-8.

[47] del Corro E, de la Roza AO, Taravillo M, and Baonza VG. Raman modes and Grüneisen parameters of graphite under compressive biaxial stress. Carbon 2012;50(12):4600-6.

[48] Hanfland M, Beister H, and Syassen K. Graphite under pressure: Equation of state and first-order Raman modes. Phys Rev B 1989;39(17):12598-603.

[49] Malard LM, Pimenta MA, Dresselhaus G, and Dresselhaus MS. Raman spectroscopy in graphene. Phys Rep 2009;473(5-6):51-87.

[50] Frank O, Tsoukleri G, Riaz I, Papagelis K, Parthenios J, Ferrari AC, et al. Development of a universal stress sensor for graphene and carbon fibres. Nat Commun 2011;2:255. 
[51] Reich S and Thomsen C. Raman spectroscopy of graphite. Phil Trans R Soc Lond 2004;362(1824):2271-88.

[52] Heise HM, Kuckuk R, Ojha AK, Srivastava A, Srivastava V, and Asthana BP. Characterisation of carbonaceous materials using Raman spectroscopy: a comparison of carbon nanotube filters, single- and multi-walled nanotubes, graphitised porous carbon and graphite. J Raman Spectrosc 2009;40(3):344-53.

[53] Gupta AK, Russin TJ, Gutiérrez HR, and Eklund PC. Probing graphene edges via raman scattering. ACS Nano 2009;3(1):45-52.

[54] Roy D, Chhowalla M, Wang H, Sano N, Alexandrou I, Clyne TW, et al. Characterisation of carbon nano-onions using Raman spectroscopy. Chem Phys Lett 2003;373(1-2):52-6.

[55] Veres M, Tóth S, and Koós M. New aspects of Raman scattering in carbon-based amorphous materials. Diam Relat Mat 2008;17(7-10):1692-6.

[56] Pimenta MA, Dresselhaus G, Dresselhaus MS, Cancado LG, Jorio A, and Saito R. Studying disorder in graphite-based systems by Raman spectroscopy. Phys Chem Chem Phys 2007;9(11):1276-90.

[57] Sood AK, Gupta R, and Asher SA. Origin of the unusual dependence of Raman D band on excitation wavelength in graphite-like materials. J Appl Phys 2001;90(9):4494-7.

[58] Lucchese MM, Stavale F, Ferreira EHM, Vilani C, Moutinho MVO, Capaz RB, et al. Quantifying ion-induced defects and Raman relaxation length in graphene. Carbon 2010;48(5):1592-7. 
[59] Wu HW, Yip K, Tian FJ, Xie ZL, and Li CZ. Evolution of char structure during the steam gasification of biochars produced from the pyrolysis of various mallee biomass components. Ind Eng Chem Res 2009;48(23):10431-8.

[60] Li X, Hayashi J-i, and Li C-Z. FT-Raman spectroscopic study of the evolution of char structure during the pyrolysis of a Victorian brown coal. Fuel 2006;85(1213):1700-7.

[61] Larouche $\mathrm{N}$ and Stansfield BL. Classifying nanostructured carbons using graphitic indices derived from Raman spectra. Carbon 2010;48(3):620-9.

[62] Casiraghi C, Hartschuh A, Qian H, Piscanec S, Georgi C, Fasoli A, et al. Raman Spectroscopy of Graphene Edges. Nano Lett 2009;9(4):1433-41.

[63] Dreyer DR, Park S, Bielawski CW, and Ruoff RS. The chemistry of graphene oxide. Chem Soc Rev 2010;39(1):228-40.

[64] Gomez-Navarro C, Meyer JC, Sundaram RS, Chuvilin A, Kurasch S, Burghard M, et al. Atomic structure of reduced graphene oxide. Nano Lett 2010;10(4):1144-8.

[65] Harris PJF, Liu Z, and Suenaga K. Imaging the atomic structure of activated carbon. J Phys Condes Matter 2008;20(36).

[66] Bourke J, Manley-Harris M, Fushimi C, Dowaki K, Nunoura T, and Antal MJ. Do all carbonized charcoals have the same chemical structure? 2. A model of the chemical structure of carbonized charcoal. Ind Eng Chem Res 2007;46(18):595467.

[67] Radovic LR, Silva-Villalobos AF, Silva-Tapia AB, and Vallejos-Burgos F. On the mechanism of nascent site deactivation in graphene. Carbon 2011;49(11):3471-87. 
[68] Rotkin S and Gogotsi Y. Analysis of non-planar graphitic structures: from arched edge planes of graphite crystals to nanotubes. Mat Res Innovat 2002;5(5):191200.

[69] Liu J, Rinzler AG, Dai H, Jason HH, Bradley RK, Boul PJ, et al. Fullerene pipes. Science 1998;280(5367):1253-6.

[70] Kwiecinska B, Suárez-Ruiz I, Paluszkiewicz C, and Rodriques S. Raman spectroscopy of selected carbonaceous samples. Int J Coal Geol 2010;84(34):206-12.

[71] Eigler S, Dotzer C, and Hirsch A. Visualization of defect densities in reduced graphene oxide. Carbon 2012;50(10):3666-73.

[72] Jorio A, Ferreira EHM, Moutinho MVO, Stavale F, Achete CA, and Capaz RB. Measuring disorder in graphene with the G and D bands. Phys Status Solidi A 2010;247(11-12):2980-2.

[73] Chen C-M, Zhang Q, Yang M-G, Huang C-H, Yang Y-G, and Wang M-Z. Structural evolution during annealing of thermally reduced graphene nanosheets for application in supercapacitors. Carbon 2012;50(10):3572-84.

[74] Krishnamoorthy K, Veerapandian M, Mohan R, and Kim S-J. Investigation of Raman and photoluminescence studies of reduced graphene oxide sheets. Appl Phys A 2012;106(3):501-6.

[75] Ishimaru K, Hata T, Bronsveld P, Nishizawa T, and Imamura Y. Characterization of $\mathrm{sp}^{2}$ - and $\mathrm{sp}^{3}$-bonded carbon in wood charcoal. J Wood Sci 2007;53(5):442-8.

[76] Kim P, Johnson A, Edmunds CW, Radosevich M, Vogt F, Rials TG, et al. Surface functionality and carbon structures in lignocellulosic-derived biochars produced by fast pyrolysis. Energy Fuels 2011;25(10):4693-703. 
[77] McBeath AV, Smernik RJ, Schneider MPW, Schmidt MWI, and Plant EL. Determination of the aromaticity and the degree of aromatic condensation of a thermosequence of wood charcoal using NMR. Org Geochem 2011;42(10):1194202.

[78] Freitas JCC, Bonagamba TJ, and Emmerich FG. Investigation of biomass- and polymer-based carbon materials using 13C high-resolution solid-state NMR. Carbon 2001;39(4):535-45.

[79] Adamopoulos G, Robertson J, Morrison NA, and Godet C. Hydrogen content estimation of hydrogenated amorphous carbon by visible Raman spectroscopy. $\mathbf{J}$ Appl Phys 2004;96(11):6348-52.

[80] Fujimori T, Radovic LR, Silva-Tapia AB, Endo M, and Kaneko K. Structural importance of Stone-Thrower-Wales defects in rolled and flat graphenes from surface-enhanced Raman scattering. Carbon 2012;50(9):3274-9.

[81] Chabalala VP, Wagner N, and Potgieter-Vermaak S. Investigation into the evolution of char structure using Raman spectroscopy in conjunction with coal petrography; Part 1. Fuel Process Technol 2011;92(4):750-6.

[82] Tan P, Deng Y, and Zhao Q. Temperature-dependent Raman spectra and anomalous Raman phenomenon of highly oriented pyrolytic graphite. Phys Rev B 1998;58(9):5435-9.

[83] Smith DC and Godard G. UV and VIS Raman spectra of natural lonsdaleites: Towards a recognised standard. Spectrochim Acta A: Mol Biomol Spectrosc 2009;73(3):428-35. 
[84] Ammar MR and Rouzaud JN. How to obtain a reliable structural characterization of polished graphitized carbons by Raman microspectroscopy. J Raman Spectrosc 2012;43(2):207-11.

[85] Mochidzuki K, Soutric F, Tadokoro K, Antal Jr MJ, Toth M, Zelei B, et al. Electrical and physical properties of carbonized charcoals. Ind Eng Chem Res 2003;42(Compendex):5140-51. 


\section{Appendix A. Supplementary materials}
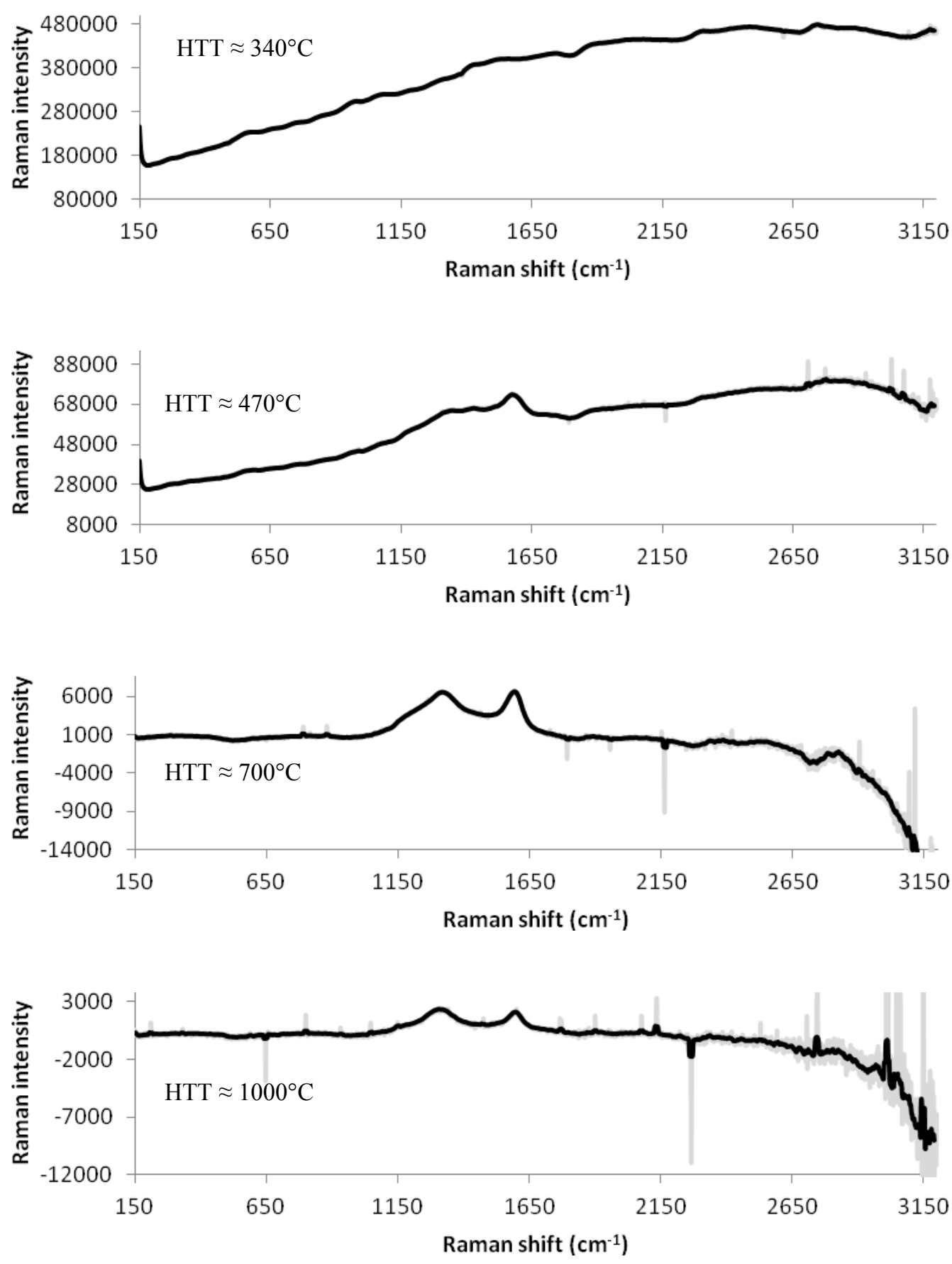

Figure S1: Raman spectra of radiata pine-derived chars produced at a range of HTTs. Grey line represents raw data (sum of 5 separate spectra) and black line represents $15 \mathrm{~cm}^{-1}$ smoothing of raw data using a moving mean. 

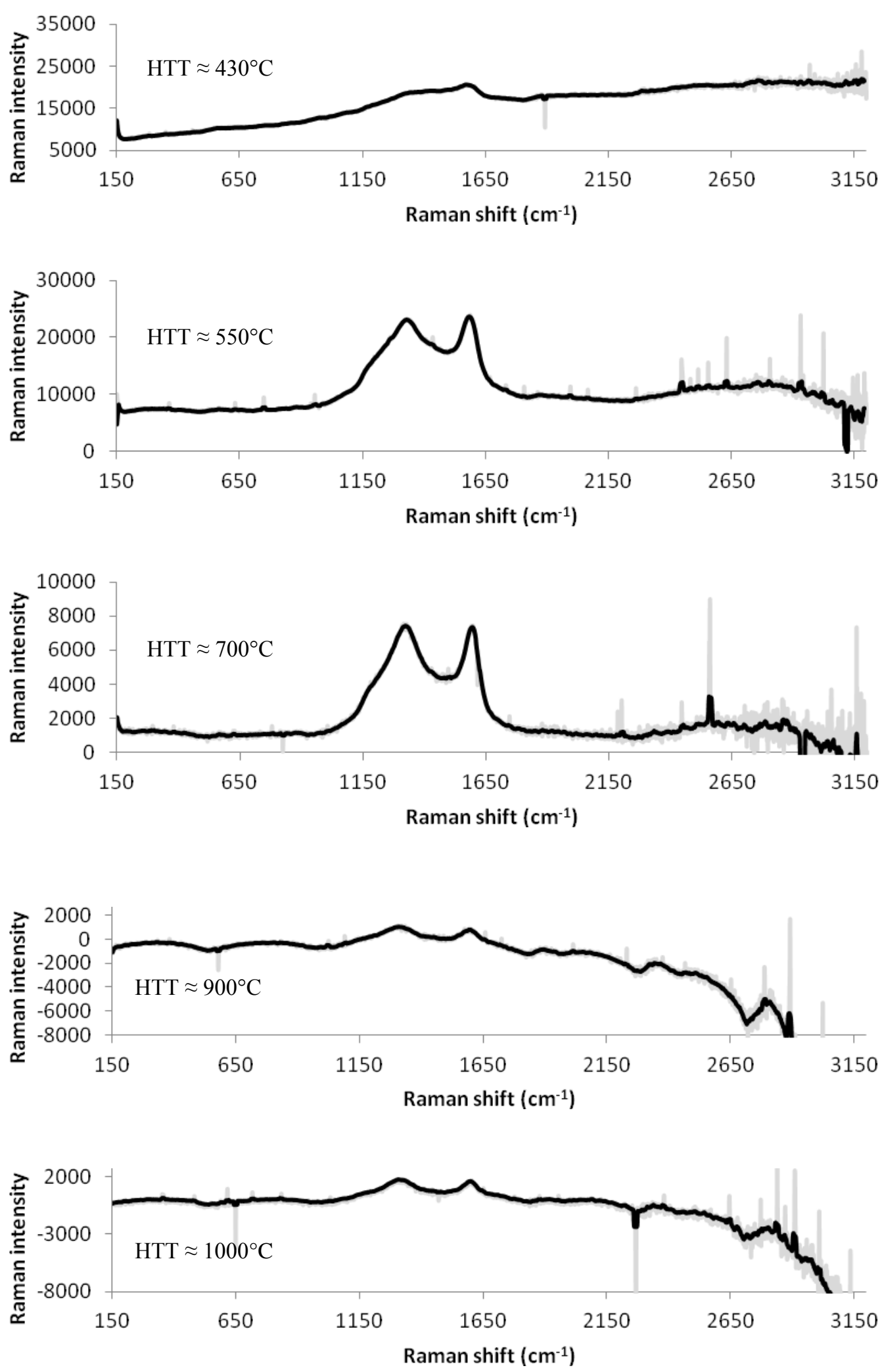

Figure S2: Raman spectra of harakeke-derived chars produced at a range of HTTs. Grey line represents raw data (sum of 5 separate spectra) and black line represents $15 \mathrm{~cm}^{-1}$ smoothing of raw data using a moving mean. 
Table S1: Sample preparation notes

\begin{tabular}{|c|c|c|c|}
\hline Name & Code & $\begin{array}{l}\text { Treatment starting } \\
\text { atmosphere }\end{array}$ & $\begin{array}{l}\text { Heating } \\
\text { equipment }\end{array}$ \\
\hline Synthetic Graphite (Air oxidised) & & Air (open furnace) & Electric tube furnace \\
\hline Single-Walled Carbon Nanotubes (Air oxidised) & & Air (open furnace) & Electric tube furnace \\
\hline Graphene Oxide (after 1-5 seconds of laser exposure) & & Air (uncovered) & Raman instrument \\
\hline Graphene Oxide (after $\approx 200$ seconds of laser exposure) & & Air (uncovered) & Raman instrument \\
\hline Graphene Oxide (after $\approx 450$ seconds of laser exposure) & & Air (uncovered) & Raman instrument \\
\hline Thermally-reduced Graphene Oxide $400{ }^{\circ} \mathrm{C}$ & & Vacuum & Electric tube furnace \\
\hline Thermally-reduced Graphene Oxide $700{ }^{\circ} \mathrm{C}$ & & Vacuum & Electric tube furnace \\
\hline Thermally-reduced Graphene Oxide $900{ }^{\circ} \mathrm{C}$ & & Vacuum & Electric muffle furnace \\
\hline Harakeke Char $430{ }^{\circ} \mathrm{C}$ & (B16) & $\mathrm{N}_{2}$ purge & Electric tube furnace \\
\hline Harakeke Char $550^{\circ} \mathrm{C}$ & (B17) & $\mathrm{N}_{2}$ purge & Electric tube furnace \\
\hline Harakeke Char $700{ }^{\circ} \mathrm{C}$ & (B11) & $\mathrm{N}_{2}$ purge & Electric tube furnace \\
\hline Harakeke Char $900{ }^{\circ} \mathrm{C}$ & (B27) & $\mathrm{N}_{2}$ purge (lid on) & Electric muffle furnace $^{1}$ \\
\hline Harakeke Char $1000{ }^{\circ} \mathrm{C}$ & $(\mathrm{B} 42 \mathrm{H})$ & Vacuum & Electric muffle furnace \\
\hline Sucrose Char $410^{\circ} \mathrm{C}$ & (B23) & $\mathrm{N}_{2}$ purge & Electric tube furnace \\
\hline Sucrose Char $550{ }^{\circ} \mathrm{C}$ & (B22) & $\mathrm{N}_{2}$ purge & Electric tube furnace \\
\hline Sucrose Char $700{ }^{\circ} \mathrm{C}$ & (B19) & $\mathrm{N}_{2}$ purge & Electric tube furnace \\
\hline Sucrose Char $900{ }^{\circ} \mathrm{C}$ & (B25) & $\mathrm{N}_{2}$ purge (lid on) & Electric muffle furnace ${ }^{1}$ \\
\hline Sucrose Char $1000{ }^{\circ} \mathrm{C}$ & (B42S) & Vacuum & Electric muffle furnace \\
\hline Radiata Pine Char $340^{\circ} \mathrm{C}$ & (N12i) & Air (restricted) & Gas-fired drum pyrolyser \\
\hline Radiata Pine Char $470{ }^{\circ} \mathrm{C}$ & (N18i) & Air (restricted) & Gas-fired drum pyrolyser \\
\hline Radiata Pine Char $700{ }^{\circ} \mathrm{C}$ & (N16i) & Air (restricted) & Gas-fired drum pyrolyser \\
\hline Radiata Pine Char $1000{ }^{\circ} \mathrm{C}$ & (B42R) & Vacuum & Electric muffle furnace \\
\hline
\end{tabular}

${ }^{1}$ Prepared in capped vessels within a furnace in a procedure similar to that used in volatile matter analysis based on ASTM method D1762-84 [66]. Although this is a common approach to carbonising samples, when compared to other methods employed in this current work these chars were more likely to have suffered oxygen damage due to poor seals using the vessel lids. 
Table $S 2: I_{D} / I_{G}$ and $\left(I_{D}-I_{V}\right) /\left(I_{G}-I_{V}\right)$ height intensity ratios

\begin{tabular}{|c|c|c|c|c|c|}
\hline \multirow[b]{2}{*}{ Colloidal Graphite } & \multicolumn{2}{|c|}{$\mathbf{I}_{\mathbf{D}} / \mathbf{I}_{\mathbf{G}}$} & \multicolumn{3}{|c|}{$\left(\mathbf{I}_{\mathbf{D}}-\mathbf{I}_{\mathbf{V}}\right) /\left(\mathbf{I}_{\mathbf{G}}-\mathbf{I}_{\mathbf{V}}\right)$} \\
\hline & 0.97 & \pm 0.03 & 0.96 & \pm & 0.04 \\
\hline Synthetic Graphite & 0.61 & \pm 0.03 & 0.50 & \pm & 0.04 \\
\hline Single-Walled Carbon Nanotubes & 0.16 & \pm 0.02 & 0.11 & \pm & 0.02 \\
\hline Glassy Carbon & 1.80 & \pm 0.06 & 1.99 & \pm & 0.07 \\
\hline PAN Carbon Fibres (Tenax HTA5131) & 1.13 & \pm 0.03 & 1.37 & \pm & 0.08 \\
\hline Graphene Oxide ( $\approx 200$ seconds of laser exposure) & 0.75 & \pm 0.01 & 0.04 & \pm & 0.08 \\
\hline Graphene Oxide ( $\approx 450$ seconds of laser exposure) & 0.82 & \pm 0.01 & 0.49 & \pm & 0.03 \\
\hline Thermally-reduced Graphene Oxide $400{ }^{\circ} \mathrm{C}$ & 1.12 & \pm 0.02 & 1.19 & \pm & 0.03 \\
\hline Thermally-reduced Graphene Oxide $700{ }^{\circ} \mathrm{C}$ & 1.12 & \pm 0.04 & 1.21 & \pm & 0.08 \\
\hline Thermally-reduced Graphene Oxide $900{ }^{\circ} \mathrm{C}$ & 1.23 & \pm 0.02 & 1.35 & \pm & 0.02 \\
\hline Harakeke Char $420{ }^{\circ} \mathrm{C}$ & 0.82 & \pm 0.01 & 0.11 & \pm & 0.12 \\
\hline Harakeke Char $550{ }^{\circ} \mathrm{C}$ & 0.97 & \pm 0.02 & 0.92 & \pm & 0.03 \\
\hline Harakeke Char $700{ }^{\circ} \mathrm{C}$ & 1.01 & \pm 0.02 & 1.03 & \pm & 0.04 \\
\hline Harakeke Char $900{ }^{\circ} \mathrm{C}$ & 1.19 & \pm 0.03 & 1.40 & \pm & 0.07 \\
\hline Harakeke Char $1000{ }^{\circ} \mathrm{C}$ & 1.09 & \pm 0.02 & 1.15 & \pm & 0.03 \\
\hline Radiata Pine Char $500{ }^{\circ} \mathrm{C}$ & 0.788 & \pm 0.005 & 0.04 & \pm & 0.02 \\
\hline Radiata Pine Char $700{ }^{\circ} \mathrm{C}$ & 0.99 & \pm 0.01 & 0.98 & \pm & 0.02 \\
\hline Radiata Pine Char $1000{ }^{\circ} \mathrm{C}$ & 1.11 & \pm 0.09 & 1.18 & \pm & 0.16 \\
\hline Sucrose Char $550{ }^{\circ} \mathrm{C}$ & 0.77 & \pm 0.01 & 0.19 & \pm & 0.12 \\
\hline Sucrose Char $700{ }^{\circ} \mathrm{C}$ & 1.02 & \pm 0.03 & 1.03 & \pm & 0.05 \\
\hline Sucrose Char $900^{\circ} \mathrm{C}$ & 1.14 & \pm 0.04 & 1.25 & \pm & 0.03 \\
\hline Sucrose Char $1000^{\circ} \mathrm{C}$ & 1.10 & \pm 0.13 & 1.14 & \pm & 0.22 \\
\hline
\end{tabular}

Values with \pm representing $99 \%$ confidence intervals calculated from 5 sub-samples and assuming a normal distribution 
Table S3: Measured A band positions and $I_{A} / I_{G}$ height intensity ratios

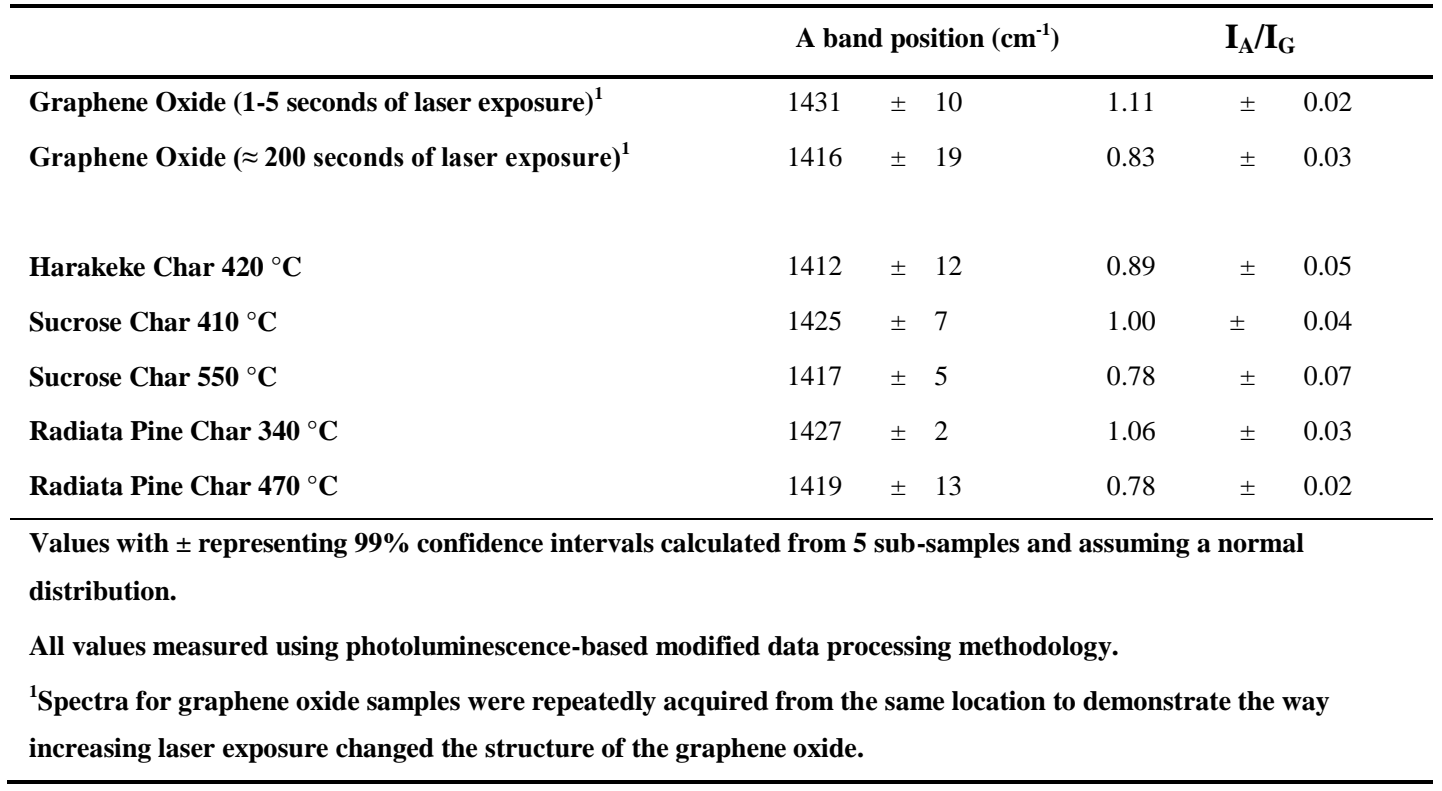


Table S4: $I_{V} / I_{G}$ height intensity ratios

\begin{tabular}{|c|c|c|c|c|c|c|}
\hline \multirow[b]{2}{*}{ Glassy Carbon } & \multicolumn{3}{|c|}{$\mathbf{I}_{\mathbf{V}} / \mathbf{I}_{\mathbf{G}} *$} & \multicolumn{3}{|c|}{$\mathbf{I}_{\mathbf{V}} / \mathbf{I}_{\mathbf{G}}$} \\
\hline & 0.23 & \pm & 0.03 & 0.20 & \pm & 0.04 \\
\hline PAN Carbon Fibres (Tenax HTA5131) & 0.59 & \pm & 0.15 & 0.68 & \pm & 0.12 \\
\hline Graphene Oxide (after 1-5 seconds of laser exposure) ${ }^{1}$ & 0.91 & \pm & 0.03 & & & \\
\hline Graphene Oxide (after $\approx 200$ seconds of laser exposure) ${ }^{1}$ & 0.30 & \pm & 0.05 & & & \\
\hline Graphene Oxide (after $\approx \mathbf{4 5 0}$ seconds of laser exposure) ${ }^{1}$ & 0.36 & \pm & 0.01 & & & \\
\hline Thermally-reduced Graphene Oxide $400{ }^{\circ} \mathrm{C}$ & 0.310 & \pm & 0.004 & 0.366 & \pm & 0.006 \\
\hline Thermally-reduced Graphene Oxide $700{ }^{\circ} \mathrm{C}$ & 0.37 & \pm & 0.04 & 0.44 & \pm & 0.02 \\
\hline Thermally-reduced Graphene Oxide $900{ }^{\circ} \mathrm{C}$ & 0.28 & \pm & 0.02 & 0.33 & \pm & 0.02 \\
\hline Harakeke Char $430{ }^{\circ} \mathrm{C}$ & 0.78 & \pm & 0.05 & 0.84 & \pm & 0.02 \\
\hline Harakeke Char $550{ }^{\circ} \mathrm{C}$ & 0.55 & \pm & 0.04 & 0.62 & \pm & 0.04 \\
\hline Harakeke Char $700{ }^{\circ} \mathrm{C}$ & 0.47 & \pm & 0.03 & 0.52 & \pm & 0.04 \\
\hline Harakeke Char $900{ }^{\circ} \mathrm{C}$ & 0.50 & \pm & 0.03 & 0.40 & \pm & 0.03 \\
\hline Harakeke Char $1000{ }^{\circ} \mathrm{C}$ & 0.36 & \pm & 0.02 & 0.42 & \pm & 0.04 \\
\hline Sucrose Char $410{ }^{\circ} \mathrm{C}$ & 0.88 & \pm & 0.03 & & & \\
\hline Sucrose Char $550{ }^{\circ} \mathrm{C}$ & 0.61 & \pm & 0.05 & 0.80 & \pm & 0.02 \\
\hline Sucrose Char $700{ }^{\circ} \mathrm{C}$ & 0.41 & \pm & 0.02 & 0.44 & \pm & 0.04 \\
\hline Sucrose Char $900{ }^{\circ} \mathrm{C}$ & 0.40 & \pm & 0.10 & 0.43 & \pm & 0.14 \\
\hline Sucrose Char $1000{ }^{\circ} \mathrm{C}$ & 0.34 & \pm & 0.06 & 0.39 & \pm & 0.11 \\
\hline Radiata Pine Char $340^{\circ} \mathrm{C}$ & 0.94 & \pm & 0.02 & & & \\
\hline Radiata Pine Char $470{ }^{\circ} \mathrm{C}$ & 0.64 & \pm & 0.01 & 0.79 & \pm & 0.01 \\
\hline Radiata Pine Char $700{ }^{\circ} \mathrm{C}$ & 0.45 & \pm & 0.00 & 0.48 & \pm & 0.01 \\
\hline Radiata Pine Char $1000{ }^{\circ} \mathrm{C}$ & 0.33 & \pm & 0.04 & 0.41 & \pm & 0.07 \\
\hline
\end{tabular}

Values with \pm representing $99 \%$ confidence intervals calculated from 5 sub-samples and assuming a normal distribution.

*Measured using photoluminescence-based modified data processing procedure.

${ }^{1}$ Spectra for graphene oxide samples were repeatedly acquired from the same location to demonstrate the way increasing laser exposure changed the structure of the graphene oxide. 
Table S5: Photoluminescence slope/ $\mathbf{I}_{G}$

Photoluminescence slope $/ \mathbf{I}_{\mathbf{G}}(\mu \mathrm{m})$

\begin{tabular}{|c|c|c|c|}
\hline Synthetic Graphite & 0.7 & \pm & 1.3 \\
\hline Dried Colloidal Graphite & 0.2 & \pm & 0.2 \\
\hline PAN Carbon fibres (HTA 5131) & 4.8 & \pm & 2.0 \\
\hline Glassy Carbon & -0.4 & \pm & 0.2 \\
\hline Graphene Oxide (1-5 seconds of laser exposure) ${ }^{1}$ & 45.7 & \pm & 4.4 \\
\hline Graphene Oxide ( $\approx 200$ seconds of laser exposure) ${ }^{1}$ & 31.0 & \pm & 4.9 \\
\hline Graphene Oxide ( $\approx 450$ seconds of laser exposure $)^{1}$ & 12.5 & \pm & 1.1 \\
\hline Thermally-reduced Graphene Oxide $400{ }^{\circ} \mathrm{C}$ & 1.1 & \pm & 0.1 \\
\hline Thermally-reduced Graphene Oxide $700{ }^{\circ} \mathrm{C}$ & 1.8 & \pm & 0.9 \\
\hline Thermally-reduced Graphene Oxide $900{ }^{\circ} \mathrm{C}$ & 0.9 & \pm & 0.1 \\
\hline Radiata Pine Char $340{ }^{\circ} \mathrm{C}$ & 57.6 & \pm & 4.1 \\
\hline Radiata Pine Char $470{ }^{\circ} \mathrm{C}$ & 18.4 & \pm & 0.6 \\
\hline Radiata Pine Char $700{ }^{\circ} \mathrm{C}$ & 0.6 & \pm & 0.2 \\
\hline Radiata Pine Char $1000{ }^{\circ} \mathrm{C}$ & 2.2 & \pm & 2.9 \\
\hline Harakeke Char $420{ }^{\circ} \mathrm{C}$ & 15.8 & \pm & 1.0 \\
\hline Harakeke Char $550{ }^{\circ} \mathrm{C}$ & 2.7 & \pm & 0.7 \\
\hline Harakeke Char $700{ }^{\circ} \mathrm{C}$ & 1.4 & \pm & 0.5 \\
\hline Harakeke Char $900{ }^{\circ} \mathrm{C}$ & -2.2 & \pm & 0.3 \\
\hline Harakeke Char $1000{ }^{\circ} \mathrm{C}$ & 1.4 & \pm & 1.3 \\
\hline Sucrose Char $410{ }^{\circ} \mathrm{C} * 1$ & 54.7 & \pm & 3.7 \\
\hline Sucrose Char $550^{\circ} \mathrm{C}$ & 28.8 & \pm & 4.9 \\
\hline Sucrose Char $700{ }^{\circ} \mathrm{C}$ & 0.9 & \pm & 0.8 \\
\hline Sucrose Char $900{ }^{\circ} \mathrm{C}$ & 0.9 & \pm & 1.8 \\
\hline Sucrose Char $1000{ }^{\circ} \mathrm{C}$ & 1.7 & \pm & 4.9 \\
\hline
\end{tabular}

Values with \pm representing $99 \%$ confidence intervals calculated from 5 sub-samples

and assuming a normal distribution.

All values measured using photoluminescence-based modified data processing procedure.

${ }^{1}$ Spectra for graphene oxide samples were repeatedly acquired from the same location in order to demonstrate the way increasing laser exposure changed the structure of the graphene oxide. 
Fig. 1: Demonstration of a data processing procedure used to measure parameters. A spectrum obtained from a $\mathrm{HTT} \approx 550^{\circ} \mathrm{C}$ sucrose-derived char is displayed as these partially carbonised chars feature both "amorphous" and "graphene-like" $1^{\text {st }}$ order Raman signals. Grey spectrum is the original spectrum after the $15 \mathrm{~cm}^{-1}$ moving mean smoothing. Dotted grey line represents the calculated "photoluminescence" slope which is then subtracted from the grey spectrum to produce the black spectrum from which the parameters are measured in this modified data processing procedure.

Fig. 2: Raman spectra of sucrose-derived chars produced at a range of HTTs. Grey line represents raw data (sum of 5 separate spectra) and black line represents $15 \mathrm{~cm}^{-1}$ smoothing of raw data using a moving mean.

Fig. 3: Graphene oxide platelet sample. The cross represents the location where Raman analysis was carried out (20\% of maximum laser power, > 100 seconds of laser exposure). Fig. 4: Raman spectra of graphene oxide (after various durations of laser exposure) and thermally reduced graphene oxides prepared at various HTTs. Grey line represents raw data (sum of 5 separate spectra) and black line represents $15 \mathrm{~cm}^{-1}$ smoothing of raw data using a moving mean.

Fig. 5: Raman spectra of commercial samples of colloidal graphite, synthetic graphite, glassy carbon, and PAN-derived carbon fibre. Grey line represents raw data (sum of 5 separate spectra) and black line represents $15 \mathrm{~cm}^{-1}$ smoothing of raw data using a moving mean. Fig. 6: Raman spectra of $\mathrm{C}_{60}$ fullerenes, $[5,6]-\mathrm{C}_{70}$ fullerenes, and single-walled carbon nanotubes. Grey line represents raw data (sum of 5 separate spectra) and black line represents $15 \mathrm{~cm}^{-1}$ smoothing of raw data using a moving mean. Note: this smoothing was probably not very appropriate for the fullerene spectra. 
Fig. 7: Plot of $\mathrm{G}$ band position as a function of heat treatment temperature for chars.

Fig. 8: Plot of D band position as a function of heat treatment temperature for chars.

Fig. 9: Drawing of a graphene-like domain (depicted within a $\approx 1 \mathrm{~nm} \times 1 \mathrm{~nm}$ square) which indicates both the approximate size, extent of condensation, and the type of order referred to in discussions of this structural feature.

Fig. 10: Plot of $I_{D} / I_{G}$ height intensity ratios as a function of heat treatment temperature for chars.

Fig. 11: Plot of $I_{V} / I_{G}$ height intensity ratios as a function of heat treatment temperature for chars. All values measured using photoluminescence-based modified data processing procedure. Horizontal guide lines represent approximate $\mathrm{I}_{\mathrm{V}} / \mathrm{I}_{\mathrm{G}}$ height intensity ratios measured for glassy carbon, graphite, and the thermally-reduced graphene oxide sample prepared at $\mathrm{HTT} \approx 700{ }^{\circ} \mathrm{C}$. Trend line uses mean values and includes chars from all three precursors.

Fig. 12: Photoluminescence slope $/ \mathrm{I}_{\mathrm{G}}$ as a function of heat treatment temperature for chars.

Fig. 13: Photoluminescence slope $/ \mathrm{I}_{\mathrm{G}}$ as graphene oxide is reduced using increasingly severe treatments

Fig. 14: Raman spectra which are examples of the most amorphous and oxygen-rich materials analysed in this current work. Lowest HTT radiata pine-derived and sucrose-derived chars compared with a graphene oxide sample analysed with the shortest laser exposure. Spectra were processed with $15 \mathrm{~cm}^{-1}$ smoothing of raw data using a moving mean followed by subtraction of the photoluminescence slope. 